\title{
Review Article \\ Novel Insights into miRNA in Lung and Heart Inflammatory Diseases
}

\author{
Amit Kishore, ${ }^{1}$ Jana Borucka, ${ }^{1}$ Jana Petrkova, ${ }^{1,2}$ and Martin Petrek ${ }^{1}$ \\ ${ }^{1}$ Laboratory of Immunogenomics and Immunoproteomics, Department of Pathological Physiology, \\ Faculty of Medicine and Dentistry, Palacky University, Hnevotinska 3, 77515 Olomouc, Czech Republic \\ ${ }^{2}$ Department of Internal Medicine I-Cardiology, Faculty of Medicine and Dentistry, Palacky University, \\ 77520 Olomouc, Czech Republic
}

Correspondence should be addressed to Amit Kishore; amitkishore.bio@gmail.com

Received 15 November 2013; Revised 3 March 2014; Accepted 21 April 2014; Published 27 May 2014

Academic Editor: Giovanna Castoldi

Copyright ( $\odot 2014$ Amit Kishore et al. This is an open access article distributed under the Creative Commons Attribution License, which permits unrestricted use, distribution, and reproduction in any medium, provided the original work is properly cited.

MicroRNAs (miRNAs) are noncoding regulatory sequences that govern posttranscriptional inhibition of genes through binding mainly at regulatory regions. The regulatory mechanism of miRNAs are influenced by complex crosstalk among single nucleotide polymorphisms (SNPs) within miRNA seed region and epigenetic modifications. Circulating miRNAs exhibit potential characteristics as stable biomarker. Functionally, miRNAs are involved in basic regulatory mechanisms of cells including inflammation. Thus, miRNA dysregulation, resulting in aberrant expression of a gene, is suggested to play an important role in disease susceptibility. This review focuses on the role of miRNA as diagnostic marker in pathogenesis of lung inflammatory diseases and in cardiac remodelling events during inflammation. From recent reports, In this context, the information about the models in which miRNAs expression were investigated including types of biological samples, as well as on the methods for miRNA validation and prediction/definition of their gene targets are emphasized in the review. Besides disease pathogenesis, promising role of miRNAs in early disease diagnosis and prognostication is also discussed. However, some miRNAs are also indicated with protective role. Thus, identifications and usage of such potential miRNAs as well as disruption of disease susceptible miRNAs using antagonists, antagomirs, are imperative and may provide a novel therapeutic approach towards combating the disease progression.

\section{Introduction}

The small microRNAs (miRNAs), 19-24 nucleotides, are noncoding, endogenous, single stranded, and evolutionarily conserved sequences. miRNAs downregulate gene expression at transcriptional or posttranscriptional level by binding to messenger RNAs (mRNAs) and preventing them from being translated into proteins [1]. They have an important role in biological processes, such as cellular development, differentiation, proliferation, and apoptosis. With the discovery of first miRNA lin-4 in 1993 [2] and later let-7 in 2000 within Caenorhabditis elegans during its developmental stage transitions $[3,4]$, as research advances, the information on miRNAs has grown exponentially and suggested them as one of the central players of gene expression regulation. For nomenclature purpose, they are numbered as per the order of their discovery. As each miRNA is able to target hundreds of transcripts, it has been estimated that miRNAs may regulate up to $30 \%$ of the protein-coding genes accounting for $1-5 \%$ of all predicted human genes [5]. For humans, to date, over 1,872 precursors hairpin sequences and 2,578 mature miRNAs have been reported (Sanger miRBase version 20; assembly count-GRCh37.p5) which can regulate important physiologi$\mathrm{cal}$ processes and pathogenesis of several diseases. This review aims to summarize the current understanding of miRNAs in lung diseases and cardiac remodeling events implicated in inflammation and their potential role as biomarkers.

1.1. MicroRNA Biogenesis, Mechanism of Action, and Regulation. miRNAs are transcribed by RNA polymerase II as long precursor (up to several hundred nucleotides) originating as RNA sequences with hairpin structure of about 70-100 nucleotides in length that constitutes the primary transcript of the miR/primary miRNAs (pri-miRNAs). 


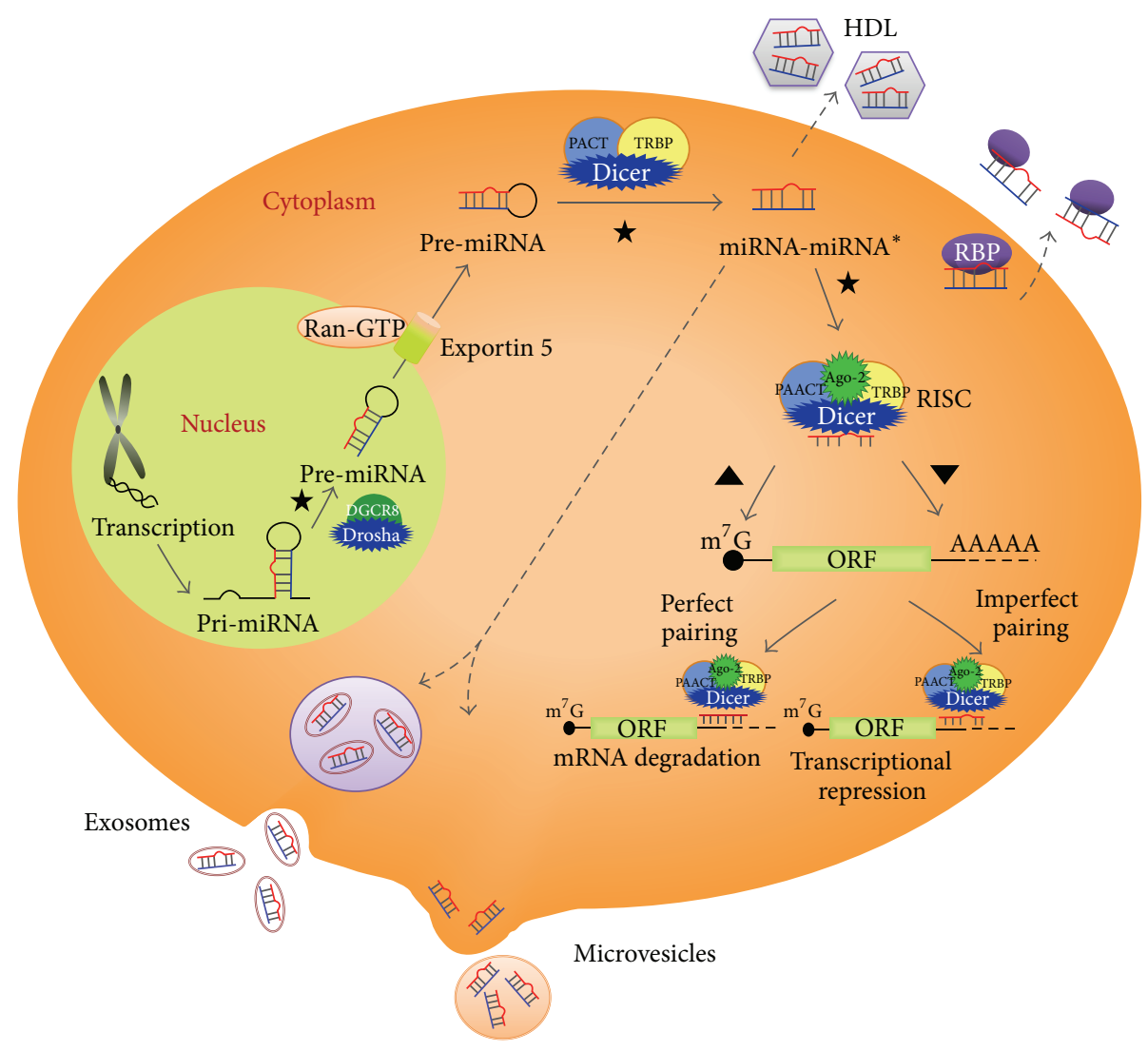

FIGURE 1: Biogenesis and role of micro-RNA (miRNA). The processing ( $\star$ ) step includes conversion of pri-miRNA to pre-miRNA through Drosha and DGCR8 and pre-miRNA to mature miRNA in the presence of dicer, PACT, and TRBP. In the mature miRNA, either of its strands is involved in RISC formation along with Ago-2. The complex is involved in transcriptional regulation ( $\mathbf{\Lambda}$ ) by binding to site for transcription factors in the $5^{\prime}$-UTR, while it functions $(\boldsymbol{\nabla})$ for mRNA degradation (by perfect pairing of its seed region) or transcriptional repression (by imperfect binding) of the target mRNA region. The mature circulatory miRNAs are also transported with microparticles such as membrane derived vesicles (exosomes and microvesicles), lipoproteins (HDL), or RNA binding proteins (RBPs) and remains protected from enzymatic degradation.

These are further processed in the nucleus by microprocessor complex consisting of RNase III enzyme Drosha and doublestranded RNA binding protein, Pasha (also called DiGeorge syndrome Critical Region 8; DGCR8) to precursor-miRNAs (pre-miRNAs) of approximately 65 nucleotides. These premiRNAs are then exported to cytoplasm by exportin-5. This exportin-5 mediated transport to the cytoplasm is energydependent, which utilizes GTP bound to the Ran protein as cofactor [6].

In cytoplasm, the hairpin loop is removed and subsequently processed by the RNase III enzyme Dicer along with two double-stranded RNA (dsRNA) binding proteins, protein activator of PKR (PACT) and transactivation response RNA-binding protein (TRBP), leaving mature miRNA duplex (miRNA-miRNA*) of about 22 nucleotides in length with mismatch base [7] (Figure 1). Further, one of the two strands of the mature miRNA is loaded into the RNA-induced silencing complex (RISC) containing enzymes of Argonaute (Ago) family and is commonly guided to the $3^{\prime}$-untranslated region (UTR) of target mRNA. miRNAs anneal with sequences via Watson-Crick base pairing, although there are some examples of miRNA interactions within mRNA coding regions, intron-exon junctions and $5^{\prime}$-UTR. With the activity of Ago-2 where it blocks translation and promotes deadenylation (degradation of poly-A tail) resulting in mRNA degradation, the two mechanisms result in gene silencing [8]. The expression level and involvement of the ribonucleases Drosha, Dicer, and Argonaute-2 (Ago2) in processing and activity of miRNAs demonstrate a relationship with the phenomenon of RNA interference.

Regarding miRNA regulation, in addition to the major stages of control during miRNA biogenesis and its subcellular localization suggested by O'Connell et al. [9] and Yue [10], single nucleotide polymorphisms (SNPs) in the binding domain (seed region) could alter miRNA function. For example, a SNP in the $3^{\prime}$-UTR of asthma susceptibility gene $H L A-G$ influences the targeting of miR-148a, miR-148b, and miR-152 [11].

1.2. miRNA Polymorphism in Regulation of Target Gene Expression. Mutations in miRNA transcripts are common and SNPs in pre-miRNAs could alter miRNA processing, expression, and/or binding to target mRNA and thus may have functional importance. Numerous reports have been 
made for the impact of single nucleotide polymorphism in miRNAs (mirSNPs) towards disease susceptibility; however, in this review, focus will be made on inflammatory lung and cardiovascular diseases.

In a case-control study for risk factor for asthma, SNPs demonstrated risk variant $\mathrm{rs} 2910164^{*} \mathrm{C}$ allele $(\mathrm{C} / \mathrm{G})$ in the pre-miRNA of miR-146a and rs2292832* $\mathrm{T}$ (C/T) miR-149 were significantly associated with lower risk of asthma [12] (Table 1). Corroborating the finding, Jimenez-Morales et al. reported $\mathrm{rs} 2910164^{*} \mathrm{C}$ (G/C) miR-146a to be significantly associated with protection against asthma among Mexican females [13]. However, the rs $2910164^{*} \mathrm{C}$ miR-146a was associated with increased risk factor for nasopharyngeal carcinoma [14]. HLA-G is an asthma-susceptibility gene and within its $3^{\prime}$-UTR rs $1063320^{*} \mathrm{G}(+13142 \mathrm{C} / \mathrm{G})$ miR-152 family (miR$148 \mathrm{a},-148 \mathrm{~b}$, and -152 ) with more stable binding to $H L A-G$ mRNA was shown to conserve the miRNA target site and to be protective against asthma only in children of asthmatic mothers. This suggested the allele-specific targeting of HLAG transcript [11, 15].

Besides, rs11614913*C (C/T) miR-196a2, a prognostic biomarker for shortened survival time $[16,17]$, was associated with increased risk for several forms of cancers including lung cancer [18-23] and congenital heart disease [24]. Also, rs $11614913^{*} \mathrm{~T}(\mathrm{C} / \mathrm{T}) \mathrm{miR}-196 \mathrm{a} 2$ and $\operatorname{rs} 3746444^{*} \mathrm{G}(\mathrm{A} / \mathrm{G})$ miR-499 were significantly associated with decreased risk for COPD [25].

In an interesting report from pulmonary tuberculosis (PTB) patients, the roles of risk alleles in miRNAs were reported to vary for disease susceptibility among different populations. Investigating the association of genetic polymorphism with $\mathrm{PTB}$, among the SNPs that regulate the Toll-like receptor- (TLR-) mediated signal pathway, it was shown that $\mathrm{rs} 3746444^{*} \mathrm{C}$ (T/C) miR-499 and $\mathrm{rs} 2910164^{*} \mathrm{G}$ (G/C) miR-146a exhibited different roles in Tibetan and Han populations [26]. Also, miR-146a is $N F-\kappa B$-dependent and regulates cytokine signaling and TLR pathways [27]. Thus, it is highly involved in pathogenesis of several inflammatory and autoimmune diseases and its genetic variants are much studied.

For chronic systemic autoimmune disease, systemic lupus erythematosus (SLE), SPI1 overexpression is suggested to have a role in its pathogenesis. A SNP rs $1057233^{*} \mathrm{~T}(\mathrm{~T} / \mathrm{C})$ in the $3^{\prime}$-UTR of SPI1 alters a target sequence for miR569 that is associated with elevated SPI1 mRNA level and with susceptibility to SLE [28]. However, another variant rs57095329* G (G/A) in the promoter region of miR-146a primary transcript was associated with SLE in Chinese [29]. Understanding the pathogenesis of SLE using combinatorial approach, novel gene-gene/gene-sex interaction was identified which included rs57095329 (G/A) miR-146a. The findings by Leng et al., implicated sex/gender, interferon pathway, and Th17/B cells as important risk contributors to SLE [30]. In a GWAS, rs2431697* T (C/T) was genetically associated with SLE in European population [31]. Further, in a recent study, rs3853839* G (G/C) in $3^{\prime}$-UTR of TLR7 was reported to affect binding of miR-3148 and was associated with increased risk for SLE [32].
Among the roles of mirSNPs in pathogenesis of cardiovascular diseases (CVDs), the mirSNPs rs5186* $\mathrm{C}(\mathrm{A} / \mathrm{C})$ in human angiotensin II type 1 receptor (AGTR1) $3^{\prime}$-UTR affecting miR-155 binding site $[35,36]$ and rs9818870 (C/T) in muscle RAS oncogene homolog (MRAS) 3'-UTR modulating miR-195 and miR-135 were proposed to be potentially involved in the hypertension (HT) and other related CVDs [37]. Recently, rs7079 (C/A) in Angiotensinogen (AGT) $3^{\prime}$ UTR affecting miR-31 and miR-584 were reported to be associated with HT [38].

For coronary heart disease, the GG genotype of miR$149 \mathrm{rs} 4846049(\mathrm{G} / \mathrm{T})$ in the $3^{\prime}$-UTR of 5,10-methylenetetrahydrofolate reductase (MTHFR) was significantly associated with the increased risk [39]. For dilated cardiomyopathy (DCM), rs11614913*T (C/T) miR-196a2 and rs3746444* G (A/G) miR-499 were found to be significantly associated with increased risks [41]. In a genotype-phenotype correlation analysis for congenital heart disease risk, CC genotype of rs11614913 (T/C) miR-196a2 was associated with a significantly increased susceptibility $\left(p=6.81 \times 10^{-6}\right)$ and increased mature miR-196a expression $(P=0.001)$ [24]. Few databases for miRNA-related genetic variants are Patrocles, dbSMR, PolymiRTS, MicroSNiPer, miRdSNP, and dPOREmiRNA [42].

These studies suggest the potentiality of genetic variant in disease susceptibility. In future, the allelic variant with low disease susceptibility could be explored in therapeutic mechanism to manage the disease progression.

1.3. miRNA in Epigenetics. miRNAs and antisense RNAs are able to direct epigenetic changes, such as histone modifications (e.g., H3K9me2, H3K9me3, and H3K27me3) and DNA methylation at specific loci, thereby evoking heritable and stable silencing of some mammalian imprinted genes. Histone modification involves Agol of RISC and the chromodomain protein Chpl that recognizes H3K9me [43]. For DNA methylation, methyl groups are transferred to carbon-5 of cytosines by DNA methyltransferases (DNMT1 or DNMT3A and $D N M T 3 B)$. Other enzymatic effectors of the epigenetic machinery include histone deacetylases (HDACs) and polycomb repressor complexes ( $P R C 1$ or $P R C 2)$. In general, $\mathrm{CpG}$ sites flanking the promoter region are hypomethylated in transcriptionally active genes and hypermethylated in inactive genes.

The downregulation of epigenetically controlled miRNAs as well as epi-miRNAs that target elements of the epigenetic machinery $[10,44]$ has most notably been reported in cancer cells [45]. The first evidence of epi-miRNAs was reported in lung cancer, where miR-29 (a-c) family was shown to directly target the de novo enzymes DNMT3A and DNMT3B [46]. In this model system, few examples of epigenetic regulation of miRNAs with oncogenic properties include hypomethylation of miR-21 [44, 47] and let-7a-3 [48] and hypermethylation of $\mathrm{miR}-34 \mathrm{~b} / \mathrm{c}[49,50]$. However, hypermethylation of $\mathrm{CpG}$ island of miR-34a has been proposed with tumor suppressor role $[44,51]$.

For the pathogenesis of autoimmune disease, such as systemic lupus erythematosus (SLE), the first report on role of 


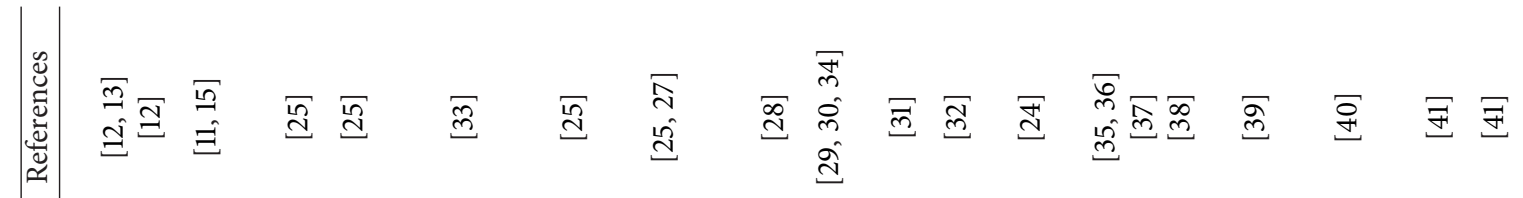

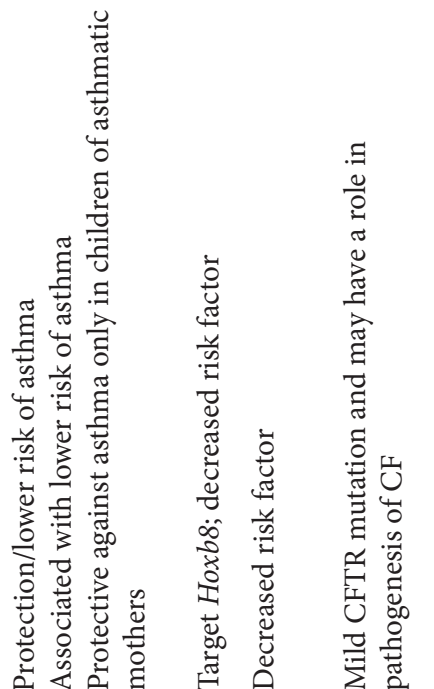

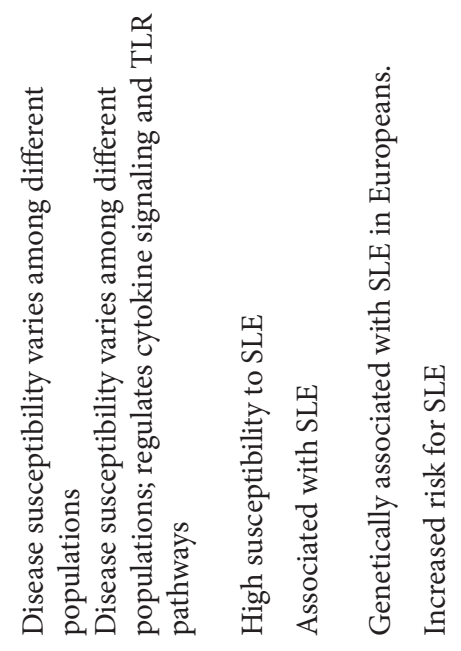

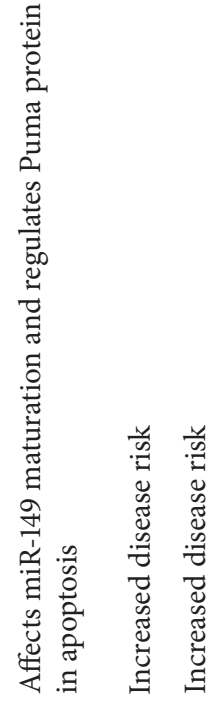

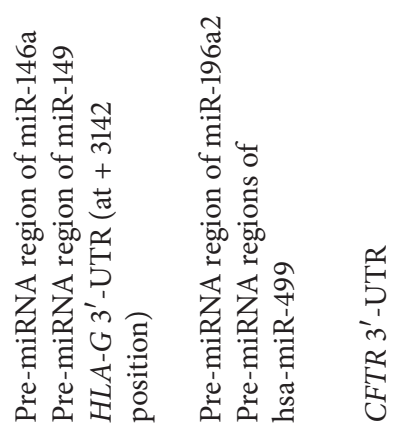

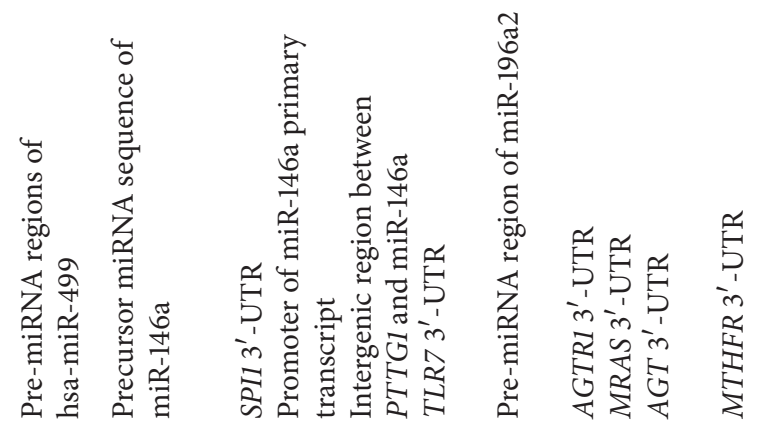

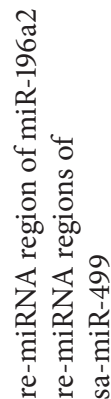

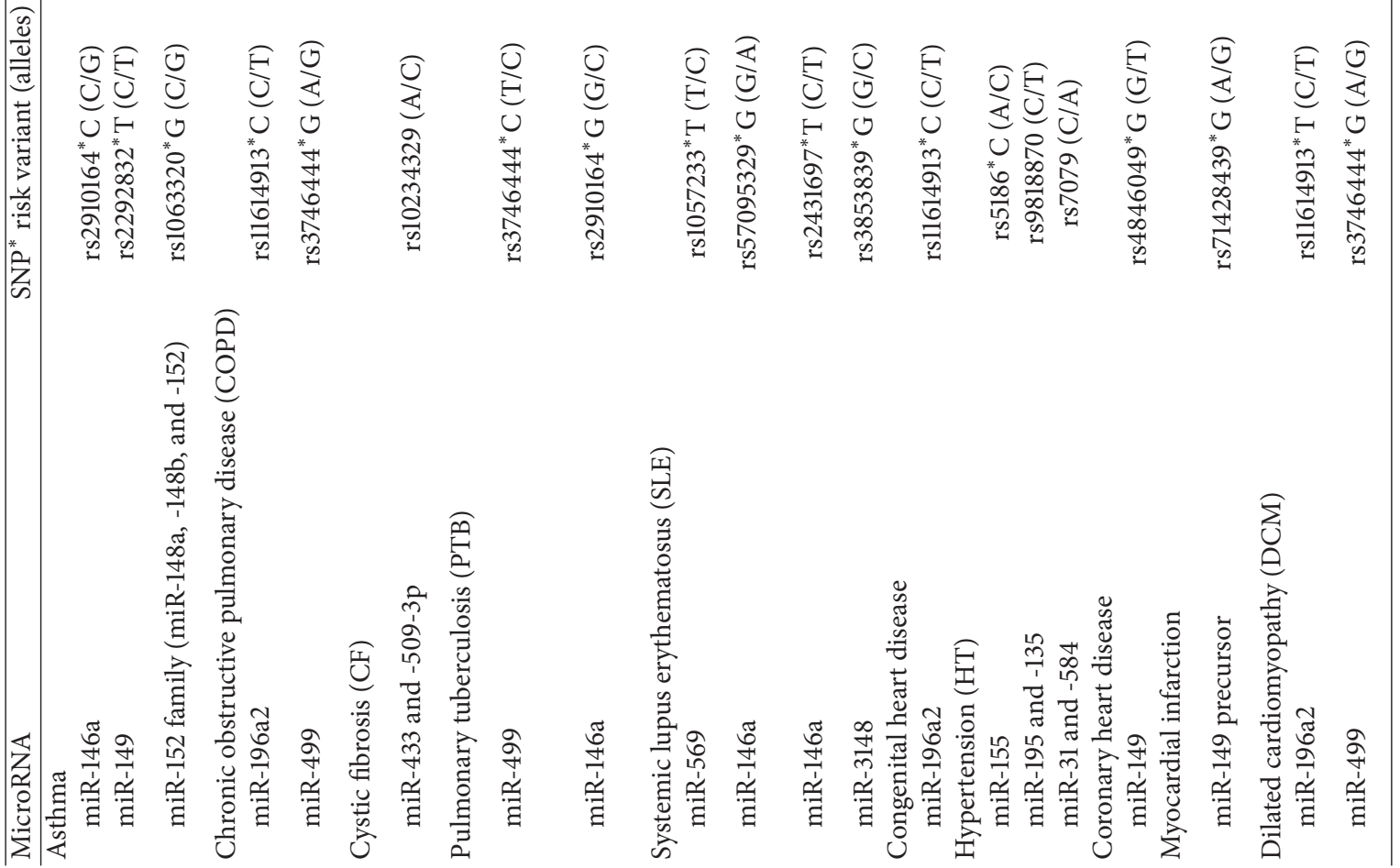


DNA methylation was made during early 1980s with certain medications, such as hydralazine and procainamide inhibiting DNA methyltransferasel (DNMT1) enzyme activity in CD4+ T cells [52], and was subsequently demonstrated by several studies $[53,54]$. A variable expression of regulatory microRNAs in lupus CD4+ T cells due to epigenetics has been described [55]. Overexpression of several miRNAs, such as miR-21, -148a [56], -126 [57], and -29b [58], is reported to affect DNA methylation machinery of lupus CD4+ T cells by targeting DNMT1 (Table 2). MiR-21 indirectly alters DNMT1 expression by targeting Ras guanyl-nucleotide-releasing protein 1 (RASGRP1) gene, which mediates the Ras-MAPK pathway upstream of DNMT1 [56]. However, miR-148a and miR126 directly inhibit DNMT1 translation via interaction with its 3 '-UTR. Aberrant overexpression of miR-29b [58] and miR126 [57] in lupus CD4+ T cells causes hypomethylation and overexpression of the methylation-sensitive genes CD1la and CD70, leading to $\mathrm{T}$ cell and $\mathrm{B}$ cell hyperactivity. Inhibition of such miRNAs expression in CD4+ T cells in patients with lupus caused reverse effects. Thus, the peculiar behavior of miRNAs could be potentially used as a prognostic biomarker for invasive phenotypes of inflammatory diseases.

Despite progress in the area of epigenetic modifications in other pathologies, the role of epigenetic factors affecting miRNA regulation in cardiac inflammatory diseases has still to be investigated. Possible differences among DNA methylation in cardiomyopathic and normal heart have been reported in humans [59] but due to lack of direct evidences the epigenetic regulation of miRNAs still remains elusive [60].

\section{Role of miRNA in Fibrosis}

The hallmark of fibrosis is tissue remodeling with excess deposition of extracellular matrix components, predominantly collagens. Recently, downregulation of miR-200 family (a-c) was reported in the lungs of mice with bleomycininduced fibrosis; restoration of miR-200 expression reversed lung fibrosis via inhibiting TGF- $\beta$, suggesting its antifibrotic role [61]. Upregulation of another miRNA, miR-21, has been related to bleomycin-induced fibrosis (Figure 2). In this case, even the delayed administration of antisense nucleotides blocking miR-21 was able to attenuate the profibrotic effect exerted by bleomycin [62-64]. Vettori et al. reviewed several studies and suggested putative miRNAs as implicated in fibrosis [65]. Amongst these, miRNAs with antifibrotic role in lungs include let-7d and miR-15b, $-16,-26 a / b$, and -29 ; for heart they include miR-132, -133, and -590; however miR17 92 cluster (miR-18a, 19a/b), -29a/b/c, and -30c are shared by both lung and heart. miRNAs with profibrotic role in lungs include miR-155, -199a/b, and -23a (clustered with -27a), in heart miR-208; miR-21 appeared in both lung and heart [65]. It has been speculated that targeting of deregulated miRNAs that are implicated in development of IPF, cardiac hypertrophy, and fibrosis may combat the progression of fibrosis in lung and heart.

\section{Recent Developments in Role of miRNAs in Respiratory Inflammation and Cardiovascular Diseases}

3.1. Role of miRNAs in Lung Inflammation. An inflammation/injury to lung tissue ignites an innate immune response. Immune cells including macrophages, monocytes, and neutrophils migrate into the lungs to protect the damaging cells and activate antimicrobial peptides and T-cell responses. It further activates proinflammatory response involving cytokines and chemokines, such as TNF- $\alpha, I F N-\gamma$, CCL5/RANTES, IL-8, and $I L-2$ as well as innate immune response involving pathogen recognition receptors mediated activation of TLRs and their adaptor proteins such as TRIF, MYD88, TIRAP, and TRAM. These inflammatory stimulators provoke aberrant expression of miRNAs in several chronic inflammatory diseases; for example, miR-146a that targets COX2 gene is highly increased in response to the stimulation of inflammatory cytokines in several cell types from COPD patients [66], whereas it has reduced levels in CD4+ Tand CD8+ T-cells in patients with severe asthma [67]. A panel of miRNAs such as let-7a and miR-21, -155, -133a, $-328,-1291$, and -1248 has been shown to differentiate between healthy and inflamed lung in asthma. Additionally, differential expression of specific miRNAs (miR-1248 and -1291) characterized unique miRNA signatures among different types of chronic inflammation such as asthma and COPD [68]. Recently, Sessa and Hata in their review have suggested the role of miRNAs as possible diagnostic and prognostic tool in lung development and pulmonary diseases such as asthma, CF, COPD, IPF, and PAH. They also discussed the potential therapeutic targets for miRNAs using different molecular strategies [8]. Focusing on therapeutic application, Fujita et al. exclusively reviewed the RNA interference (RNAi) in lung inflammatory and cancer diseases along with therapeutic drugs under clinical trials, its route of administration, drug delivery agents, and target gene [69]. The status of miRNAs expression mentioned in this review has been reported to be valid using qRT-PCR or reporter gene assays in majority of the studies. These abnormal immune responses in response to environmental stimuli, infections, and aberrant genetic behavior including miRNA expression may lead to pathological processes and development of various pulmonary diseases [70]. In this review, focus will be made primarily on inflammatory pulmonary and cardiovascular diseases.

3.1.1. Asthma. Asthma is a chronic inflammatory lung disease stimulated by aberrant allergen-specific CD4+ T helper-2 (TH2) secreting cytokines, IL-2, -4, -5, -9, and -13 in response to various stimuli, such as allergens, infections, and air pollutants. It is characterized by elevated serum IgE, airway hyperresponsiveness, mucus hypersecretion, and eosinophil accumulation in the lung [73]. In asthma, upregulated miRNAs include let-7b and miR-21, -106a, -126, -145, -146a, -146b, $-155,-181$, and -221 , while the downregulated are let-7 family and miR-20b, -133a, -146a, -146b, and -28-5p (Table 3).

During the innate host response to allergens, miRNA expression with elemental regulatory signals has been linked 
TABLE 2: Role of miRNAs in epigenetic regulation of lung inflammatory diseases and cardiac remodeling.

\begin{tabular}{lcc}
\hline Disease and miRNA & Putative role in disease susceptibility & References \\
\hline $\begin{array}{l}\text { Idiopathic pulmonary fibrosis (IPF) } \\
\text { miR-17 92 cluster }\end{array}$ & $\begin{array}{c}\text { Hypermethylation and increased DNMT-1 expression: } \downarrow \text { miR-17 92 in } \\
\text { lung biopsies and lung fibroblasts from IPF patients }\end{array}$ \\
SLE & Targets RASGRP1 and alters DNMT1 activity; DNA hypomethylation \\
miR-21 & in disease state & Targets DNMT1; hypomethylation \\
miR-29b & Inhibits DNMT1 \\
miR-126 & Inhibits DNMT1 \\
miR-148a & [56] \\
Myocardial infarction & Acetylation regulates miR-21 promoter in myocardial infarction \\
miR-21 & [56] \\
\hline
\end{tabular}

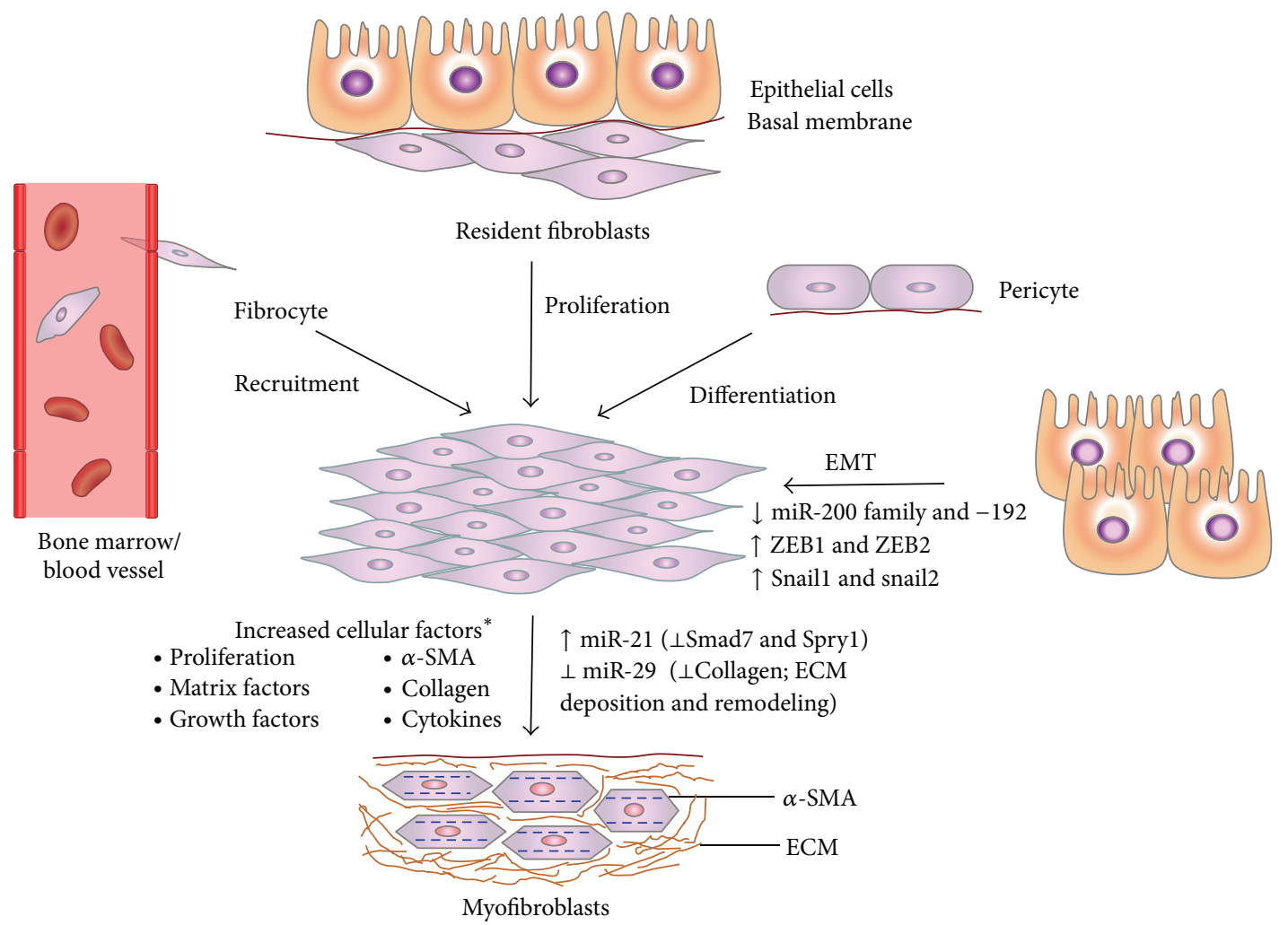

FIGURE 2: Role of miRNAs in mechanism of fibrosis. The downregulation of miR-200 and -192 (inhibits epithelial-mesenchymal transition, EMT) and miR-29 (prevents the deposition of extracellular matrix, ECM) promotes fibrosis. Further, miR-21 amplifies TGF- $\beta$ signaling and promotes myofibroblasts phenotype in fibrosis. This is characterized by increased cellular factors ${ }^{*}$ and expression of alpha-smooth muscle actin ( $\alpha$-SMA) and EDA-fibronectin.

to TLR signaling leading to activation of inflammatory pathways [27]. Notably, miR-21 is among the most overexpressed miRNAs in the inflamed lung tissue and in human airway epithelial cells in response to IL-13 treatment. It suppresses TLR-2 signaling in an animal model of asthma [74]. In a mouse model, it was shown that miR-126 expression was regulated by TLR4 or MyD88 deficient pathways and its antagonism suppressed the effector function of lung TH2 cells along with the development of allergic airways disease [75].
Also, for the bronchial smooth muscle cells, the reduction of miR-133a seems to increase bronchial hyperactivity in an animal model of asthma by increasing the expression of RhoA [76] (Table 3). Further, aberrant expression of miRNAs from primary bronchial epithelial cells including miR-152 family (miR-148a, -148b, and -152) that regulates plasma soluble human leukocyte antigen-G (sHLA-G) is associated with asthma [11, 15]. Recently, substantial differences were demonstrated in exosomal miRNAs profile including let-7 
(a-e) and miR-200 (-200b and -141) families between healthy subjects and patients with unprovoked, mild, and stable asthma [77].

3.1.2. Chronic Obstructive Pulmonary Disorder (COPD). Chronic obstructive pulmonary disease (COPD) is characterized by both chronic inflammation in the airway and systemic inflammation. It is due to combination of emphysema and chronic asthmatic bronchitis leading to impairment of lung function. However, the molecular mechanism of COPD has not been fully elucidated [78]. Proper diagnosis at early stages has remained a major challenge for COPD management. In this context, role of miRNA in COPD development and progression has been well illustrated in several studies (Table 3).

In COPD, miRNAs such as miR-146a and miR-155 have been demonstrated with a regulatory role in inflammation. Cytokine-stimulated prostaglandin $\mathrm{E}_{2}$ production and miR146a expression in cultured fibroblasts correlated with clinical severity of COPD suggesting a pathogenic role of miR-146a [66]. A recent study evaluated the expression of 863 human miRNAs in blood cells of lung cancer and COPD patients along with healthy controls and identified 14 miRNAs as significant for comparing lung cancer and COPD patients [79]. Amongst these, eight miRNAs (hsa-miR-26a, -641, $-383,-940,-662,-92 a,-369-5 p$, and -636) were significant for differentiating COPD patients and healthy controls. The differentially expressed hsa-miR-26a acts as regulator of NF$\kappa \mathrm{B}$ pathway by the regulation of its target gene, activating signal cointegrator 1 complex subunit 3 (ASCC3) [79]. Sanfiorenzo et al. identified a six-plasma miRNA panel that was able to discriminate between NSCLC patients and COPD patients and an eleven-plasma miRNA panel that could distinguish non-small-cell lung carcinoma (NSCLC) patients from healthy subjects [80].

3.1.3. Cystic Fibrosis (CF). Cystic fibrosis (CF) is a monogenic disease caused by mutations in the CFTR gene and is characterized by mucus airway obstruction, neutrophildominated airway inflammation, and bacterial infection that lead to massive proinflammatory phenotype in the lung. The developmental processes, characterized by bronchial wall thickening and tissues fibrosis, are mediated by the production of reactive oxygen species and metalloproteases [8].

Role of miRNAs in CF has been reported by several workers; among them, Oglesby et al. firstly described miR126 in CF. In particular, miR-126 targets TOM1 protein, a negative regulator of $I L-1 \beta, T N F-\alpha$, and $L P S$ signaling pathway. The downregulation of miR-126 in CF patients correlated with upregulation of TOM1 and downregulation of $N F-\kappa B$-regulated IL-8 secretion [102]. Moreover, in human airway epithelial cells, three miRNAs, miR-384, -494, and -1246, were shown to inhibit CFTR and $3^{\prime}-\mathrm{UTR}$ of $\mathrm{Na}^{+}-\mathrm{K}^{+}$$\mathrm{Cl}^{-}$cotransporter SLC12A2 which is important in regulating chloride transport [100]. Similarly, miR-101 and miR-494 were able to suppress CFTR activity by up to $80 \%$, under in vitro study [101]. A higher level of miR-155 in CF through hyperexpression of cytokines, such as IL-8 in CF lung epithelial cells in in vitro [107, 108] and in vivo models [106], suggests the role for miRNA in CF pathogenesis. Further, to understand the aberrant expression mechanism of miR-155 in CF, two mRNA-destabilizing inflammatory RNA-binding proteins, KSRP and TTP, were shown to have an antagonistic role in miR-155 biogenesis [109]. Regarding the biosynthesis of CFTR, miR-138 was shown to alter the expression of several encoding genes associated with CFTR and it also regulates CFTR expression through its interactions with the transcriptional regulatory protein SIN3A [103]. Recently, high expression of miR-101, -144, -145, -215, -223, -509-3p, and -494 in CF cells was shown to be as dynamic regulators of CFTR $[98,104,105,108,110]$.

3.1.4. Idiopathic Pulmonary Fibrosis (IPF). Idiopathic pulmonary fibrosis (IPF), defined as a specific form of chronic, progressive fibrosing interstitial pneumonia of unknown cause which is associated with the histopathologic and/or radiologic pattern of usual interstitial pneumonia (UIP) [135], has the largest epidemiological impact and the worst prognosis among interstitial lung disease. Approximately $10 \%$ of the microRNAs are significantly deregulated in IPF lungs [111].

In IPF, the regulation of epithelial-mesenchymal transition (EMT) through inhibition of let-7 family members by transforming growth factor $\beta 1$ (TGF- $\beta 1$ ) and a high expression of HMGA2 in alveolar epithelial cells were demonstrated both in vitro and in vivo [111]. Related to progression of fibrosis through myofibroblast differentiation, a high expression of miR-21 was shown in the lungs of bleomycin-treated mice as well as IPF patients and its inhibition reduced the severity of fibrosis [62]. In addition, miR-29 was shown to be involved in EMT and target profibrotic genes in human fetal lung fibroblasts [116] and in bleomycin-induced pulmonary fibrosis in mice [117]. Recently, miR-21 and miR-155 expressions were shown as detectable and stable in serum of patients with IPF [64]. Interestingly, miR-200 family members were shown to reverse the fibrogenic activity of pulmonary fibroblasts in IPF [61]. Comparative analysis of miRNA and gene expression microarray data in IPF revealed enrichment of the TGF $\beta 1$, Wnt, Sonic Hedgehog, p53, and VEGF pathways and complex regulatory networks [116]. In addition, pathway analysis indicated that altered microRNA expression may be associated with HGF signaling, cholecystokinin/gastrinmediated signaling, and IGF-1 signaling, among others, in fibrotic lung disease [63].

3.1.5. Other Inflammatory Lung Diseases. Despite the critical role of miRNA in inflammatory response, limited studies have focused on its role in inflammation-induced acute lung injury (ALI)/acute respiratory distress syndrome (ARDS) [122]. The roles of miRNAs such as Let-7a and miR-21, $-32,-127,-146 a,-155,-181 b,-466-5 p$, and $-466-3 p$ have been suggested to be involved in this severe pathology (Table 3 ). However, the knowledge of this condition has remained limited to establish their role as biomarker for early prevention, prognosis, and therapeutics role in possible therapy; the roles 


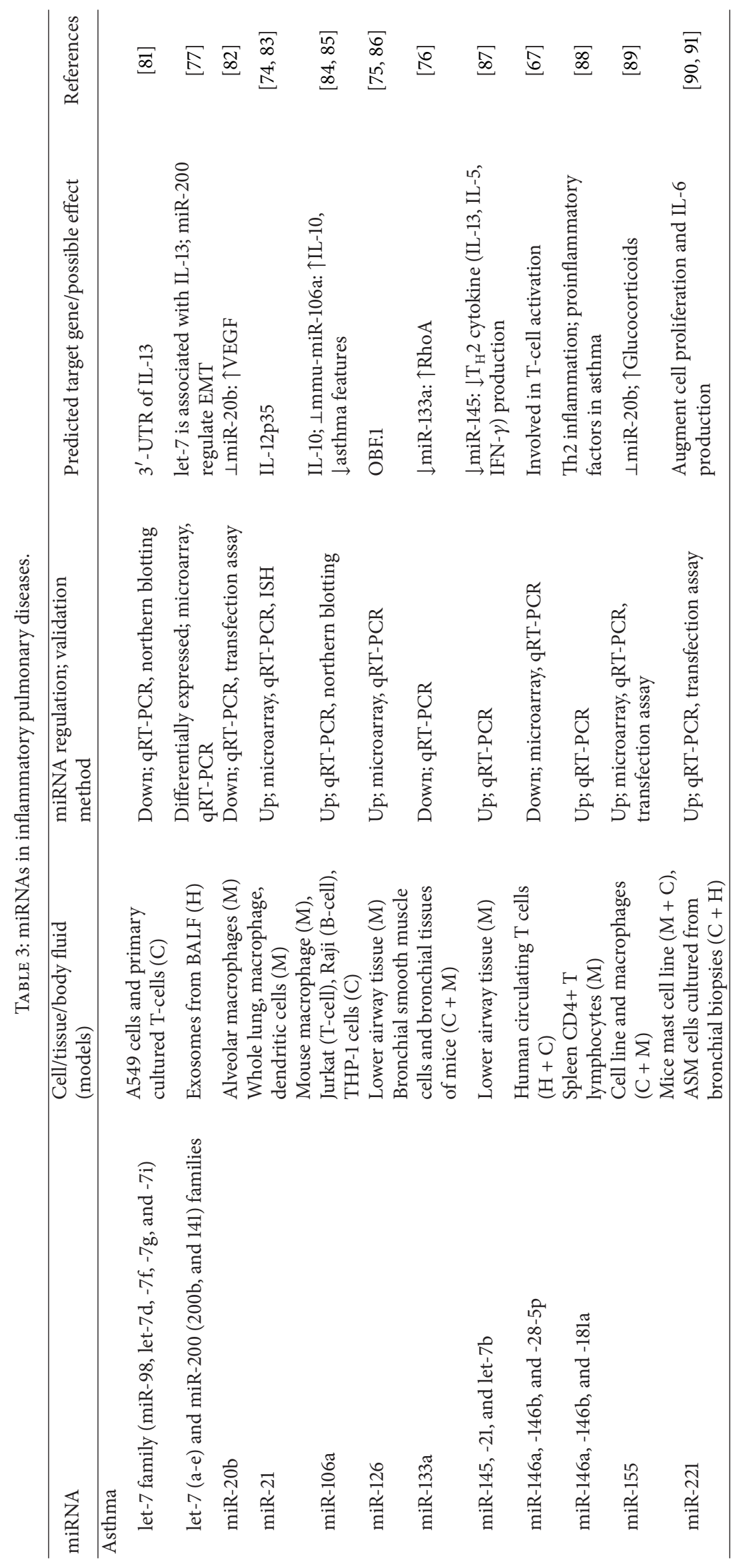




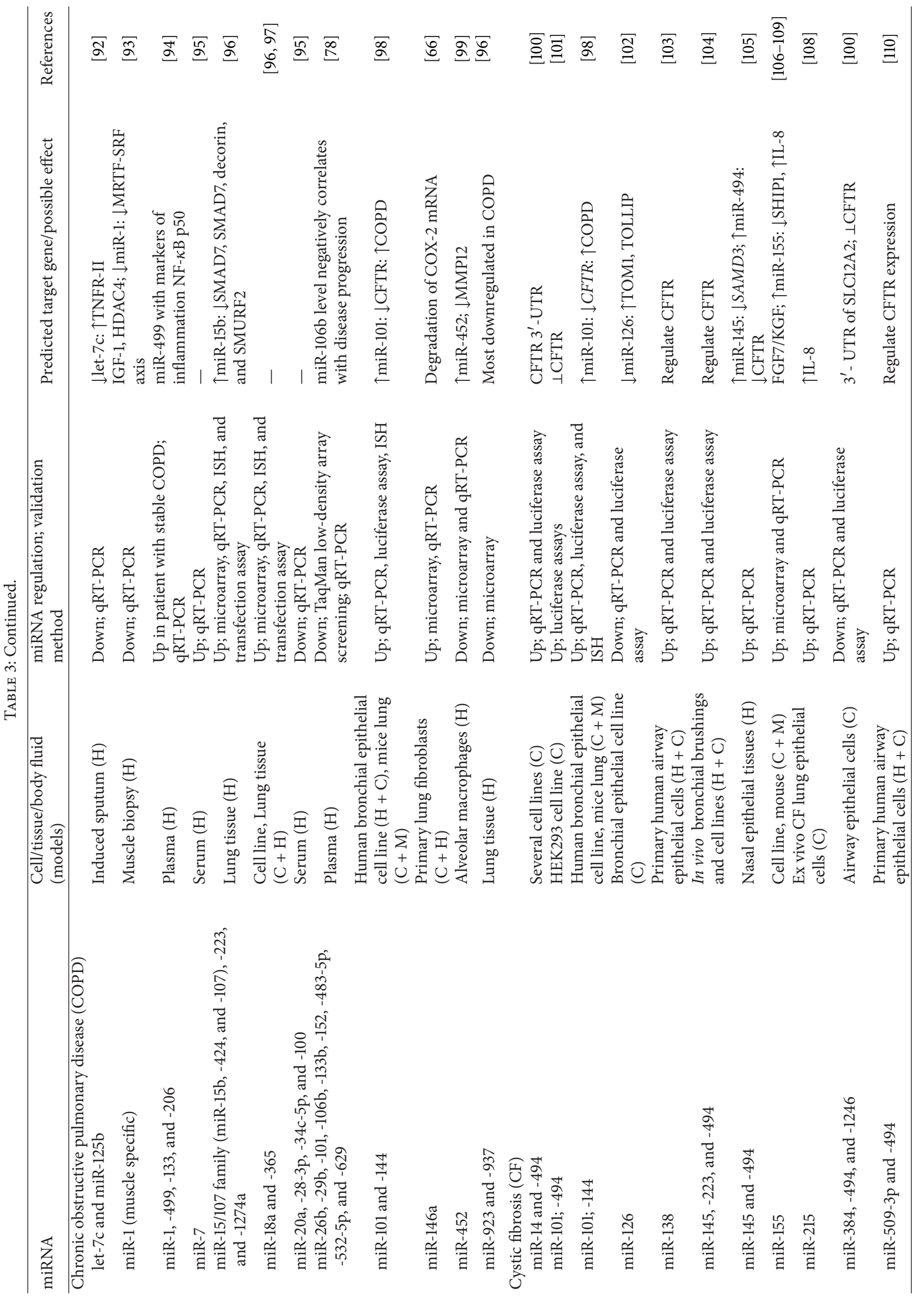




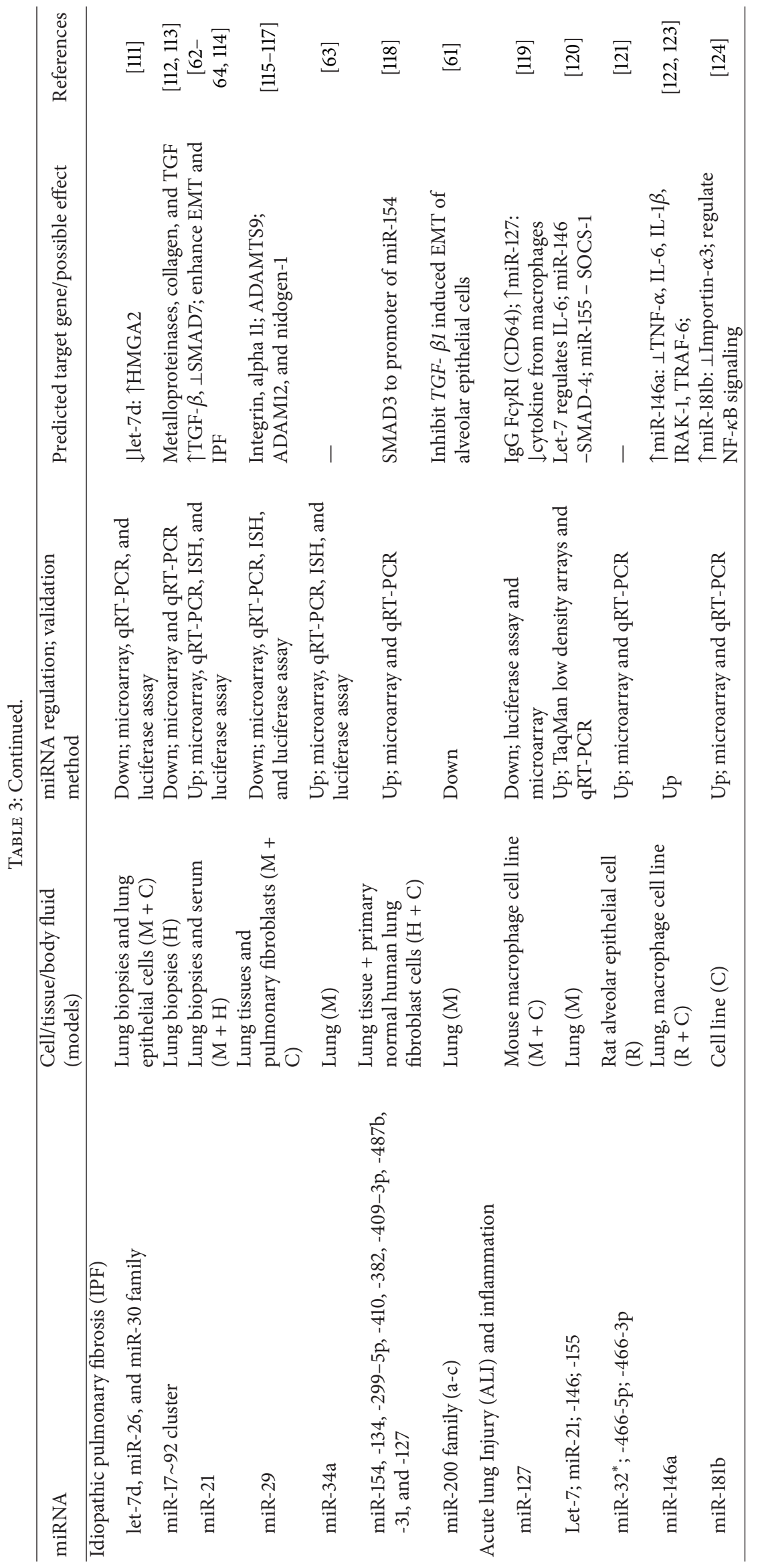




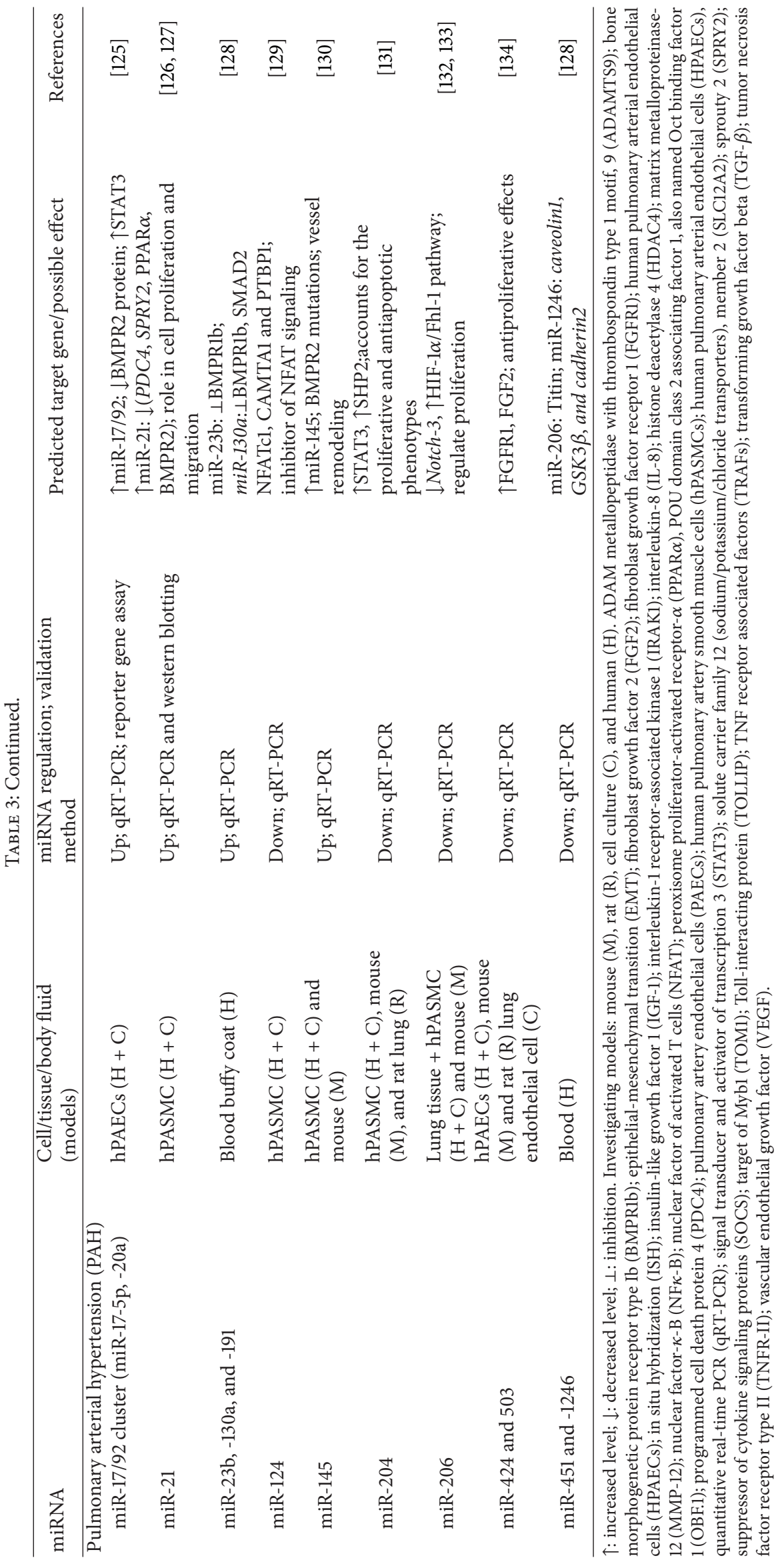


of miRNAs mentioned above are also needed to be validated and confirmed by more studies.

3.1.6. Pulmonary Artery Hypertension (PAH). Pulmonary arterial hypertension $(\mathrm{PAH})$ is a disease of the pulmonary vasculature characteristic by vascular remodeling associated with obliteration of pulmonary arterioles and formation of plexiform lesions composed of hyperproliferative endothelial and vascular smooth-muscle cells [134]. Wei et al. identified a spectrum of downregulated (miR-451 and -1246) and upregulated (miR-23b, -130a, and -191) miRNAs in PAH patients, suggesting these circulating miRNAs as potential biomarker for early disease detection [128]. Besides, several miRNAs (miR17/92 cluster, -21, -23b, -130a, and -145) detected in PAH were reported to be connected with disrupted BMPR2 pathway in PAH (Table 3). Sarkar et al. confirmed the role of miR-21 in smooth muscle cell proliferation and migration with increased expression of miR-21 in pulmonary artery smooth muscle cells (PASMCs) [126]. By contrast, miR-204 expression in PASMCs was downregulated in both human and rodent PAH model, and delivery of the synthetic miR204 significantly reduced disease severity in animal model [131]. Similarly, in vivo administration of miR-21, -424, and -503 ameliorated PAH $[134,136]$. Collectively, these observations propose reestablishment of normal miRNA level as a potential therapeutic approach.

3.2. Role of miRNAs in Cardiac Remodeling. Inflammation plays a key role in cardiac function and remodeling during progression of cardiovascular diseases (CVDs). Biological processes affecting fibroblasts, extracellular matrix proteins, coronary vasculature, cardiac myocytes, and ionic channels are involved in this remodeling process $[137,138]$. The vascular cell adhesion molecule-1 (VCAM-1) expression is induced through $\mathrm{NF}-\kappa \mathrm{B}$ mediated pathway and proinflammatory cytokines such as IL- $1 \beta$, IL- 6 , and TNF- $\alpha$. The VCAM-1 as well as chemokine receptor-2 (CCR2) induces the interaction of vascular endothelial cells (ECs) with monocytes and $\mathrm{T}$ lymphocytes which triggers the early atherosclerotic plaques $[139,140]$. At transcriptional level, understanding of miRNAs biological functions in the cardiovascular system in physiological and pathological condition is considered to be potentially crucial for CVD prevention, diagnosis, and therapy $[138,141]$. For miRNA profiling of cardiac remodeling in response to inflammation, serum based extracellular miRNAs have been extensively utilized as noninvasive and reliable diagnostic tool (Table 4 ). The pathological process of the myocardium is associated with an altered expression profile of genes that are important for cardiac function. Regulation of cardiac gene expression is complex, with individual genes being controlled by multiple enhancers that regulate specific expression patterns in the heart. Increasing evidences indicate that miRNAs play important role in myocardial pathology adding a new point of view of how cardiac gene expression is regulated.

Recent reviews provide an overview of specific miRNA signatures with dysregulated level in CVDs [138].
These are transported as extracellular microRNAs during cell-to-cell RNA communication and considered as important diagnostic markers [179, 193-195]. For example, Small and Olson explored the role of miRNAs in heart development and pathological cardiac remodeling along with their potential therapeutic targets. They also suggested exciting possibilities for the therapeutic manipulation of miRNA-regulated processes in several cellular mediated diseases that are difficult to modulate therapeutically [196]. Further, extending this approach for therapeutic inhibition of cardiovascular miRNAs, van Rooij and Olson summarized the current chemistries (tiny LNA, LNADNA miximer, antagomir, and $2^{\prime}-\mathrm{F}-2^{\prime}$-MOE miximer) for targeting miRNAs [197]. In a study, significant increase in serum level of miR-1 and -133 in patients with cardiovascular diseases such as acute myocardial infarction, unstable angina pectoris, and cardiomyopathy indicated its implication in myocardial damage [198]. In particular, specific set of miRNAs is involved in atherosclerosis, myocardial infarction, heart failure, myocardial hypertrophy, and fibrosis. Here, we summarize and highlight some of the most investigated miRNAs in this field (Table 4), focusing on the main groups of miRNAs involved in myocardial remodeling.

3.2.1. Atherosclerosis. Atherosclerosis (AS), a chronic inflammatory disease affecting major arteries, represents one of the causes of myocardial infarction, ischemic stroke, and peripheral artery disease [199]. miRNAs, such as miR-21, 146a, and -155 , are involved in most of the inflammatory diseases [142] and have been implicated in the development of AS; for example, miR-21, -34a, -146a, -146b-5p, and -210 were significantly upregulated in vulnerable atherosclerotic plaques [143] (Table 4). While miR-155 was shown to promote AS by repressing Bcl6 in macrophages, its inhibition reduced the expression of CCL2, which recruits monocytes to atherosclerotic plaques [200]. Mechanistically, miR-155 (proinflammatory) and miR-146 (anti-inflammatory) were reported to regulate dendritic cell functions in atherosclerotic inflammation [201]. As far as the functional aspects of this process, miR-155 is upregulated by macrophage-derived miR342-5p through Akt-1 inhibition, which results in stimulation of inflammatory mediators such as Nos 2 and IL6 in macrophages [202]. On adverse, miR-155 was also suggested to possess protective feature as it prevented development of AS and its progression by regulating inflammatory response and MAP3 K10 of MAPK pathway [203]. This contrasting effect of miR-155 may be context dependent and differ between early and advanced stages [204]. Other miRNAs implicated in AS, for example, miR-27 [201] or miR-214, were shown to possess cardioprotective effects against ischaemic injury in mouse model by controlling excessive calcium influx and cell death [205].

Also, suppression of $\mathrm{NF}-\kappa \mathrm{B}$ signaling and inhibition of atherosclerotic lesion by systemic delivery of miR-181b in apolipoprotein E-deficient mouse model with reduced expression of miR-181b suggested the protective role for AS [146]. The two different miRNAs from different sources 


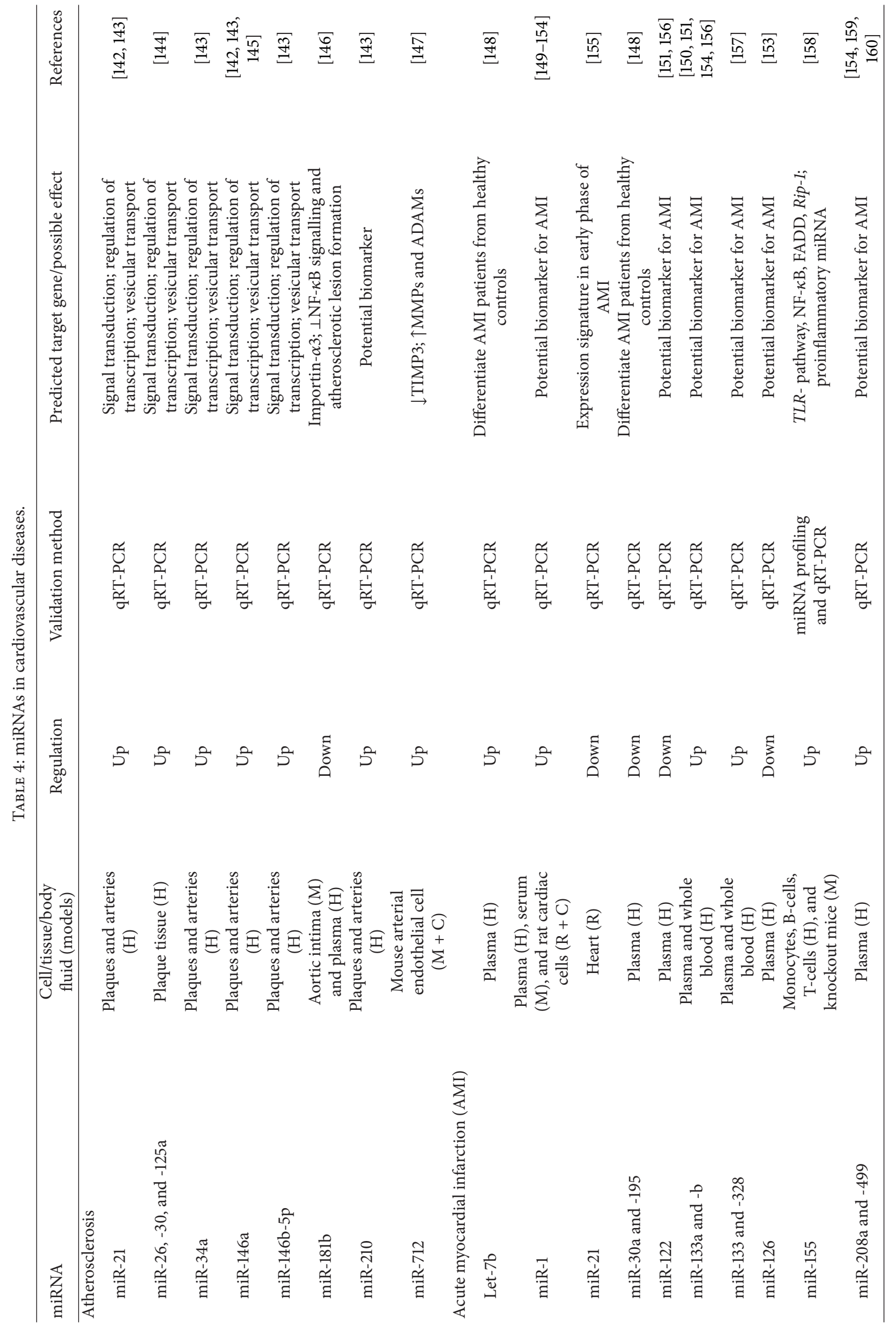




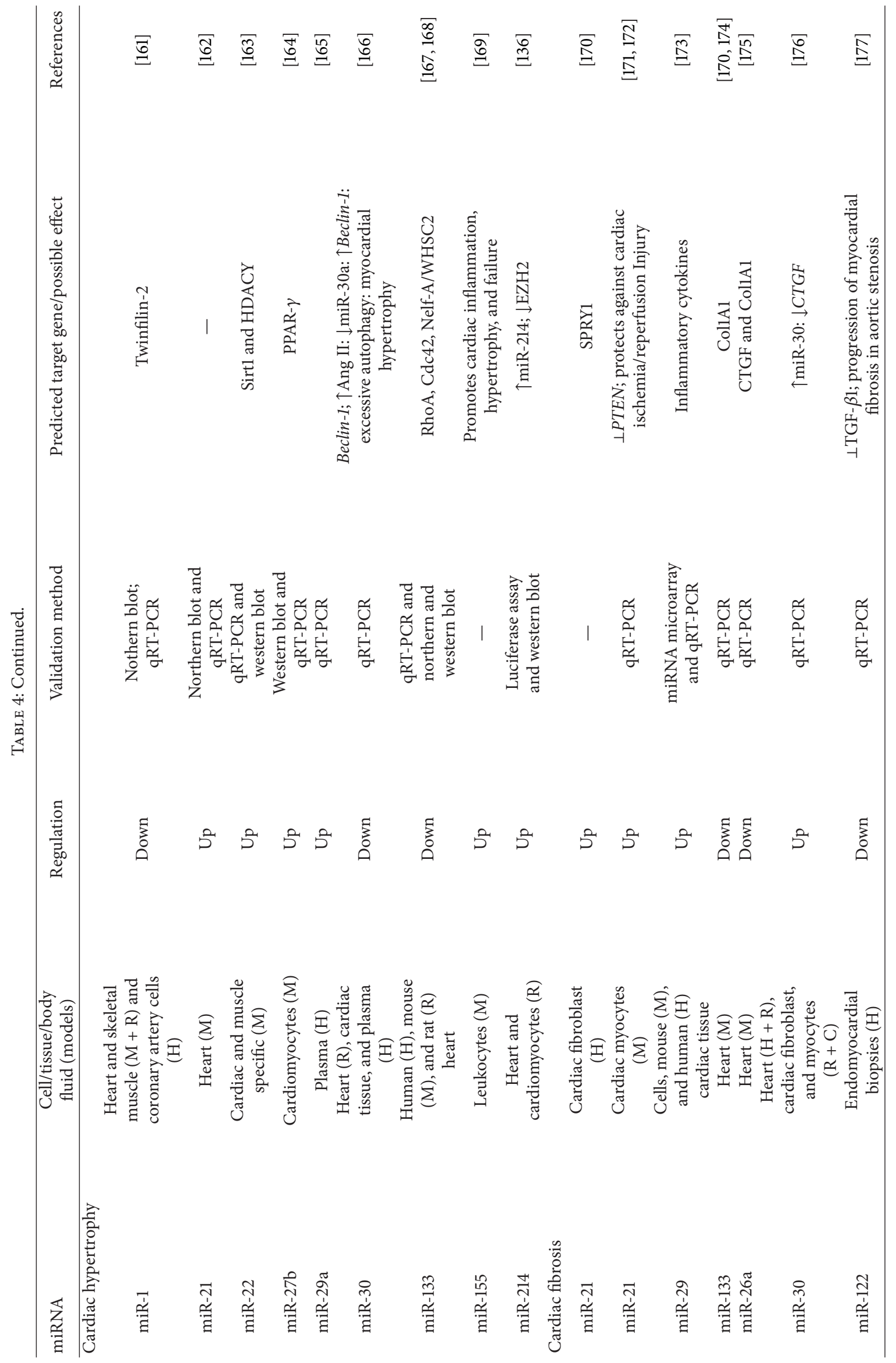




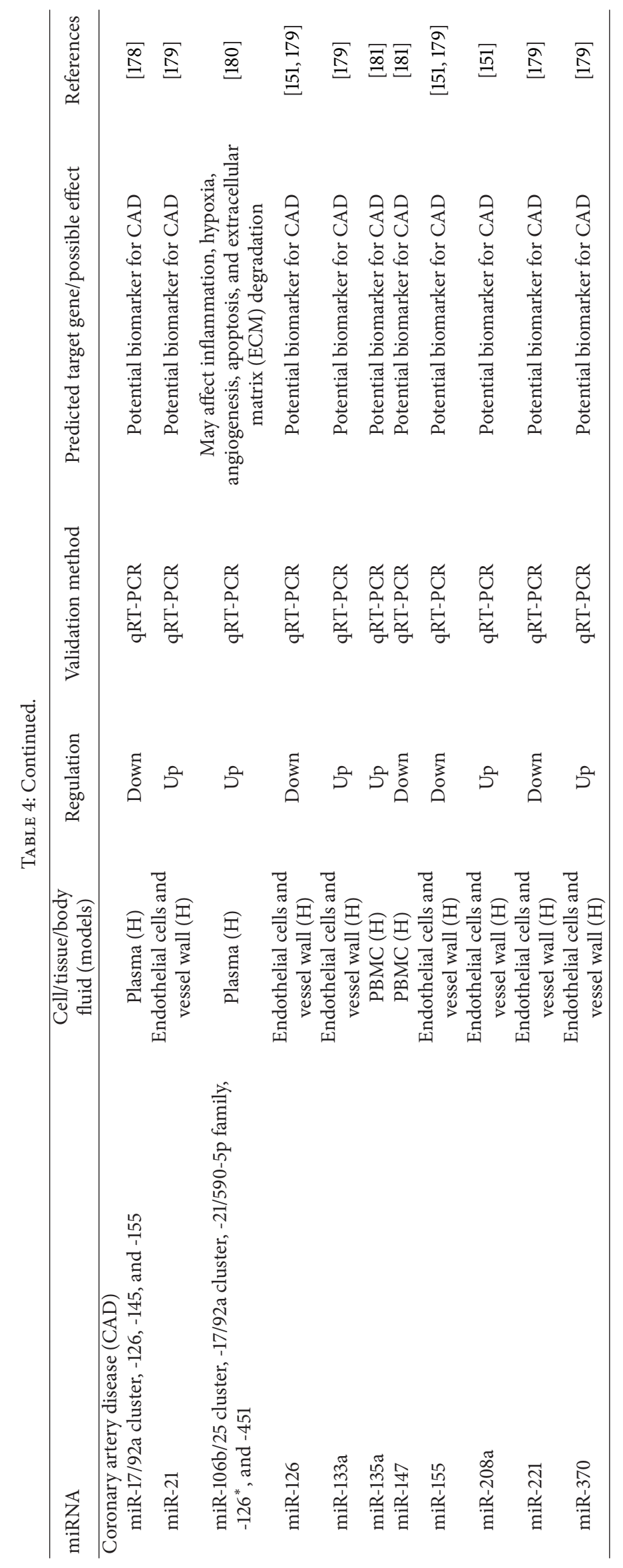




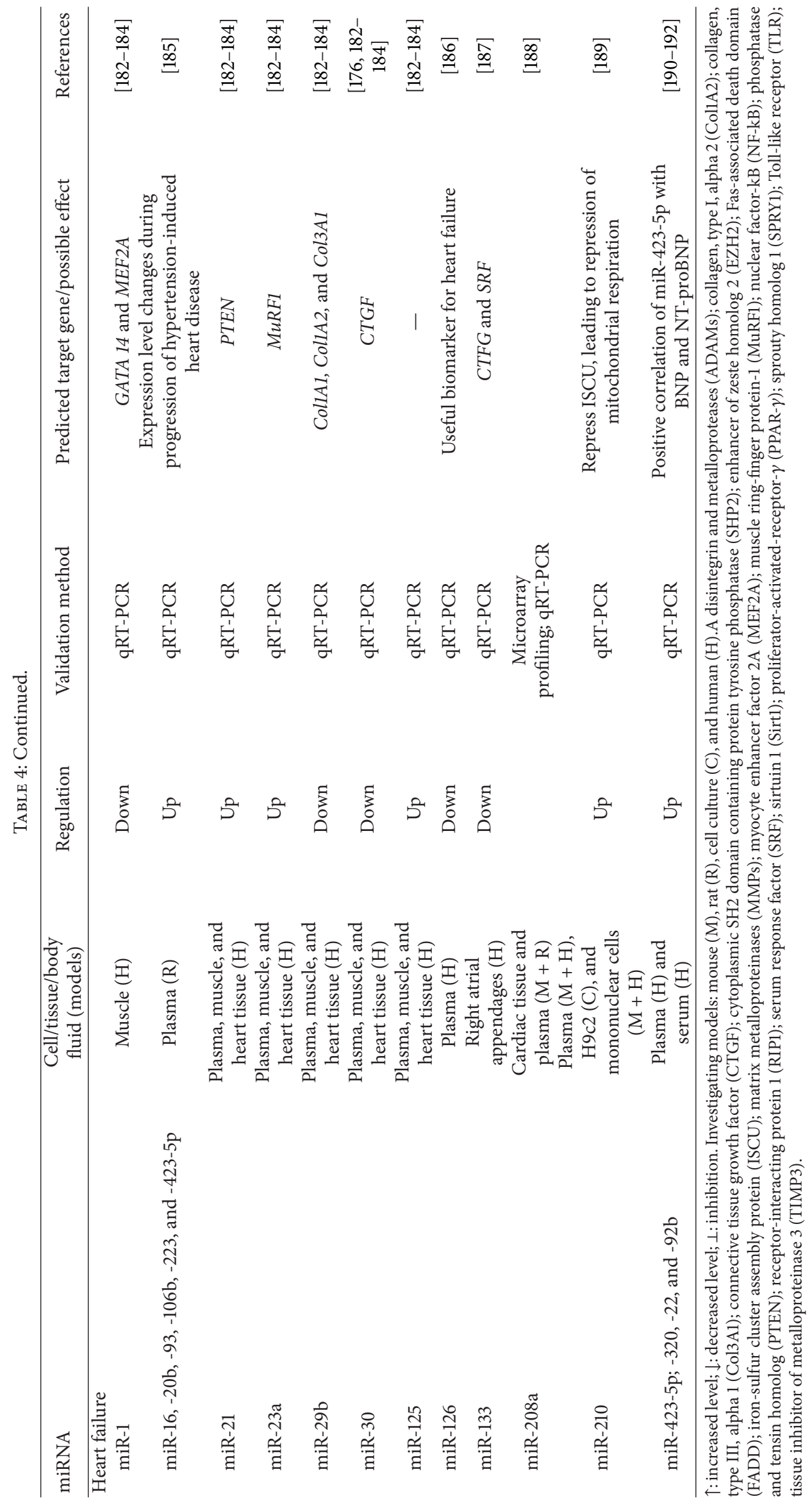


(human or mouse), sharing a common seed sequence essential for target recognition and binding, have been demonstrated to exert similar role. Recently, inhibition of miR-712 by anti-miR-712 was reported to rescue TIMP3 expression and prevented arthrosclerosis in murine model. From comparative analysis, human miR-205 was also found to have the same seed sequence that targets TIMP3 [147]. Further, they suggested that targeting these mechanosensitive "atheromiRs" and systemic delivery of miRNAs may serve as novel therapeutic approach to treat chronic inflammatory diseases such as atherosclerosis.

3.2.2. Acute Myocardial Infarction. Acute myocardial infarction (AMI) is complex diseases that result from interplay between genetic and environmental factors [206]. Cardiac regulatory proteins, cardiac troponins $\mathrm{T}(\mathrm{cTnI})$ and $\mathrm{I}(\mathrm{c} T \mathrm{Tn})$, that control the calcium mediated interaction between actin and myosin have been currently the preferred markers for myocardial injury due to their high sensitivity and specificity for the diagnosis of AMI. However, there is still need for early clinical diagnostic markers for AMI. Further, circulating miRNAs are believed to be closely linked to myocardial injury; moreover, due to the cell-specific physiological functions and miRNAs stability in plasma, serum, and urine, they are being explored as sensitive biomarkers of AMI [207]. Ai et al. observed upregulation of muscle-enriched miR-1 and proposed it to be potential predictor of AMI [149]. Additional miRNAs that were found to be upregulated in patients with AMI included miR-133a, -133b, -208b, -499, and -499-5p, whereas miR-122, -223 , and -375 were lower than in controls $[150,151,156]$.

3.2.3. Myocardial Hypertrophy and Fibrosis. Cardiac hypertrophy is characterized by an increase in cell size and/or myofibrils without change in myocyte number. Among miRNAs involved in myocardial hypertrophy/fibrosis, miR-133 was suggested to play a fundamental role. Its downregulation was associated with myocardial hypertrophy in mouse and humans $[167,168]$. A reduced expression of miR-133a was observed in experimental model of angiotensin II-dependent hypertension in both myocardial hypertrophy and fibrosis. In fact, miR-133a targets collagen lal (CollA1), which represents the main collagen fibres involved in myocardial fibrosis observed in angiotensin II-dependent hypertension [174]. Downregulation of miR-133 could promote fibrosis by targeting connective tissue growth factor, a potent profibrotic molecule. A reduced expression of miR-133b was observed in all patients regardless of heart failure etiology [208] and during cardiac hypertrophy [209].

Concerning circulatory miRNAs, miR-29a is a common marker for both cardiac hypertrophy and fibrosis reported to be upregulated in patients with hypertrophic cardiomyopathy [165]. MiR-29 family was also related to cardiac fibrosis. Kin et al. found upregulated miR-29 in abdominal aortic aneurysm [173] (Table 4), and van Rooij et al. observed dramatically downregulated miR-29 in the region of fibrotic scar after acute myocardial infarction [210]. Another miRNA, miR30 , regulates a key profibrotic protein, connective tissue growth factor (CTGF) which contributes to collagen synthesis. It downregulates CTGF level and thus controls structural changes in the myocardium extracellular matrix [176]. Similarly, another target of miR-30, beclin-1 (an autophagyrelated gene), also exhibited an inverse relationship. The overexpression of beclin-1 gene promotes Angiotensin IIinduced myocardial hypertrophy by downregulation of miR30 in cardiomyocytes through excessive autophagy [166].

3.2.4. Heart Failure. The pathogenesis and clinical manifestations of heart failure are complex and involve disruption of normal mechanisms that regulate cardiomyocyte gene expression, growth, survival, and function. Cardiac interstitial cells and vascular cell also actively participate in disease process, resulting in altered myocyte-nonmyocyte signalling, cardiac fibrosis, and decreased vascular density. Currently only B-type natriuretic peptide (BNP) and probrain natriuretic peptide (NT-proBNP) are clinically established diagnostic biomarkers for heart failure. However, evaluation of HF progression along with the appropriate timing for therapeutic interventions in the $\mathrm{HF}$ patient is important from the perspective of clinical management [185] and new markers are therefore needed.

In this context, signature expression patterns of specific miRNAs that are consistently aberrantly expressed in heart failure patients were described: miR-1, -29, -30, -126, and 133 are found to be downregulated in heart failure patients, whereas miR-21, -23a, -125, -210, -195, -199, and -423-5p are among the upregulated [182-184]. Further, circulating levels of plasma miR-16, -20b, -93, -106b, -223, and -423-5p were significantly increased during hypertension-induced heart failure in mouse model [185]. Plasma concentration of miR423-5p was significantly elevated in heart failure patients due to dilated cardiomyopathy (DCM) and positively correlated with NT-proBNP level [190]. In a recent study, biopsy of the right atrial myocardium tissue from 83 patients revealed enrichment of miR-1 and miR-133 within cardiac muscle and the decreased level of miR-133a was associated with signs of heart failure [187].

Among several miRNAs, miR-21 was implicated in several cardiac remodelling issues (Table 4). It is expressed in all characteristic cardiovascular cell types, including vascular smooth muscle cells, endothelial cells, cardiomyocytes, and cardiac fibroblasts, and target genes such as programmed cell death 4 (PDCD4), phosphatase and tensin homology deleted from chromosome 10 (PTEN), sproutyl (SPRY1), and sprouty2 (SPRY2) involved in proliferative vascular disease [211]. Reports indicate miR-21 to be involved in pathogenesis of in vitro cardiomyocyte hypertrophy and indirectly in vivo via fibroblasts. In contrast, some studies report an antihypertrophic effect of miR-21 in isolated cardiomyocytes, a reduction in infarct size by miR-21, or an inhibition of $\mathrm{H}_{2} \mathrm{O}_{2}$ induced apoptosis of isolated cardiomyocytes [212]. Also, miR-21 exhibits a protective role by reducing myocyte apoptosis and ischemic heart failure/reperfusion injury through suppression of phosphatase and tensin homolog (PTEN), a negative regulator of the AKT pathway $[171,172]$. Thus, owing 
to its role in both pro- and antihypertrophic, the role of miR21 in cardiac disease remains controversial. The reasons for the discrepancy between these studies are unclear; however, miR-21 is expressed predominantly in cardiac fibroblasts, not cardiomyocytes $[170,212]$, primarily due to comparatively increase in the number of cardiac fibroblast cells. Overall, it is indicated that miR-21 inhibits endothelial cell proliferation and migration, whereas it promotes cardiomyocyte and fibroblast survival upon myocardial ischaemia/reperfusion. The potential role of miR-21 in cardiac fibrosis and hypertrophy is still debated and measures such as global knockdown or overexpression of miR-21 in the reperfused myocardium are suggestive to provide an insight on postinfarct remodeling [212].

\section{4. miRNA as Biomarker}

Aberrant miRNA expression has been associated with various human diseases and its determination can differentiate between normal and diseased tissue [213]. Besides cancer, altered miRNA expression has been reported in lung inflammatory diseases such as asthma, chronic obstructive pulmonary disorder (COPD), cystic fibrosis (CF), idiopathic pulmonary fibrosis (IPF), pulmonary artery hypertension (PAH), and cardiovascular diseases such as atherosclerosis, myocardial infarction (MI), cardiac fibrosis, and coronary artery disease $[8,213]$. Banerjee and Luettich reviewed the miRNAs as potential biomarkers for the major smokingrelated diseases including cancer, $\mathrm{COPD}, \mathrm{PAH}$, and cardiovascular diseases [213]. Also, based on observations from human and mouse model they suggested miRNAs as regulators of biological responses, such as inflammation innate immune response, including TLR signaling. Identification of particular miRNAs within cells, tissues, or cellular free body fluids, with altered expression correlated with disease and/or its clinical development, could thus be exploited as potential biomarker for diagnosis and management. The potential of miRNAs to serve as biomarkers is further supported by their innate characteristics, such as high conservation between species, presence of highly stable cell-free form in the circulation, and omnipresence-being isolated from most of the cells, tissues, and body fluids including serum, plasma, urine, saliva, breast milk, tears, semen, exhaled breath condensate, and bronchoalveolar lavage fluid (BALF); importantly they can be detected in small sample volumes using quantitative real-time PCR (qRT-PCR) [5]. The observed stability, that is, resistance to enzymatic RNase A digestion and other conditions such as boiling, extreme $\mathrm{pH}$, extended storage, and several cycles of freeze-thaw in serum [214] as well in plasma, is also relevant in this context [215].

4.1. Circulating miRNAs. Circulating miRNAs, also known as extracellular miRNAs, are cellular free in nature. The origin of circulating miRNAs, stable existence in extracellular environment, and their distinct roles, has remained elusive [193, 216]. They could be divided into two major groups, microparticles associated and microparticles nonassociated miRNAs $[217,218]$. Circulating miRNAs are exported from cells and are transported with microparticles such as membranederived vesicles (exosomes and microvesicles), lipoproteins (HDL), and other ribonucleoprotein complexes such as Nucleophosmin-1 (NPM-1) and Ago2-miRNA (Figure 1) that protect them against enzymatic degradation [193, 219]. Arroyo et al. characterized circulating miRNA complexes in human plasma and serum. For miRNA profiling, they quantified 88 plasma and 66 serum miRNAs by RT-qPCR and revealed that the vesicle-associated plasma miRNAs represent the minor fraction, whereas up to $90 \%$ of circulatory miRNAs were present in a nonmembrane-bound form with ribonucleoprotein complex [217].

Importantly, there are differences in miRNAs expression and abundance between the source, that is, serum and plasma and/or body fluids/other components [220-222]. For example, in the same individuals, higher miRNA concentrations were obtained from serum samples compared to the corresponding plasma samples. This difference was suggested due to release of additional miRNAs from blood cells into serum during the coagulation process. Plasma was suggested as sample of choice, representing true repertoire for circulatory miRNAs [221]. Still, concentration of circulating miRNAs in plasma may be affected by multiple factors such as sample processing, release by specific cells into the circulation, and also miRNA stability [223]. Recently, miRNAs from exosomes [77] and platelets [224] have also been explored and have distinct expression profile [218]. For research, one should consider in which components (body fluid types and microparticles) circulating miRNAs are investigated.

The differential expression of tissue-specific miRNAs in circulation has been explored as potential circulating biomarkers for specific organ pathologies involved in lung or heart disease, for example, skeletal muscle specific miR$1,-499,-133$, and -206 in plasma of COPD patients [94] and cardiac specific miR-133a, -208a, and -499 in MI [154, 159, $160,223]$. Most of the miRNAs are significantly detectable in the diseased serum or plasma samples and this thus supports the possibility of using the expression levels of these organspecific circulatory miRNAs as biomarkers for site-specific pathologies [221].

However, there are limitations and factors to be addressed prior to application of miRNAs in diagnostic purpose. These include optimal standardization in the approaches for obtaining sample (invasive/noninvasive), source (local/systemic), and nature (extra-cellular/cellular/tissue-based) of biological material and minimal variability in sample collection and its processing. Moreover, lack of data on miRNA specificity/sensitivity among different reports and its overlapping role in different diseases also hampers its applicability.

4.2. Current Developments in miRNA Based Approaches. The preliminary step includes quality estimation of miRNA. Among the few possibilities, 2100 Bioanalyzer, a lab on-chip technology from Agilent Technologies, offers both qualitative and quantitative estimation of miRNAs. For miRNA discovery, high-throughput deep sequencing (next-generation sequencing) platforms such as HiSeq 2000/Genome Analyzer IIX/Solexa (Illumina), SOLiD (ABI), GS FLX+, or 
454 sequencing (Roche) are available [225]. Amongst these, HiSeq 2000 solid phase technology supports massively parallel sequencing using a reversible terminator based method with least error rate and is most successful and widely adopted [226]. In the process of identification of miRNAs, several computational approaches have been developed that complement the experimental analysis. These in silico resources include MiRscam, miRSeeker, Phylogenetic shadowing, miRank, miRDeep, MiRanalyzer, proMiR II, mirabela, triplet-SVM, Vmir, RNA micro, BayesMiRNAFind, One-ClassMirnaFind, miPred, Srnaloop, and findMiRNA [226]. Additionally, miRandola, an extracellular circulating miRNA database, allows users to deduce their potential biological functions and their relation with phenotypes [227].

Most commonly used techniques for establishing miRNA signatures in body fluids include high throughput determination of differential miRNA gene expression using miRNA microarrays [228] and their further validation using quantitative real-time PCR (qRT-PCR). However, the best approach for absolute quantification is qRT-PCR and its two variations, that is, stem-loop (TaqMan probe based) RT-PCR [229] and poly(A)-tailed (SYBR green based) RT-PCR [230], with improved specificity and sensitivity for miRNA expression analysis. Nonetheless, most published studies present conflicting data and have limitations in their cross-comparison of miRNA-expression profiles due to technical variations that include various reference genes being used to normalize the miRNA levels measured in body fluids and differences in blood collection (e.g., heparin contains an inhibitor of Taq polymerase) [231].

The optimal quantification of the target miRNAs involves data normalization using either stable reference genes under the study or accumulative values of the large scale miRNAprofiling data under study. However, as reference miRNAs (RNU6B, 5S rRNA) are reported to vary with the sample source and study type, former approach is suggested as preferred due to usage of global measure [232]. The addition of synthetic miRNAs from an unrelated organism such as C. elegans (cel-miR-39, cel-miR-54, and cel-miR-238) during miRNA isolation has also been proven useful for normalizing the data obtained by qRT-PCR [215]. Cheng et al. report plasma/serum volume as the best factor with which to standardize the amount of input miRNA [152]. However, studies are necessary for the identification of an accurate normalization protocol and empirical validation of stable endogenous control miRNAs for each type of body fluid.

For studying epigenetic modification, preliminary analysis involves methylated-DNA immunoprecipitation-chip (MeDIP-chip), validated differential methylation loci by bisulfate (BS) PCR and high throughput sequencing (BSseq). The miRNA promoters in different cell types have been identified by genome-wide profiling of promoter associated chromatin marks through Dnase I hypersensitivity (DHS) mapping, chromatin immunoprecipitation (ChIP) followed by large-scale microarray analysis (DHS/ChIPchip) or next-generation sequencing (DHS/ChIP-seq). DHS mapping identifies sites of open chromatin that are accessible to factors that influence gene expression. Active promoters are characterized by open chromatin regions enriched for both the H3K4me3 and H3K79me2 [42].

The use of miRNA as target for therapeutic tool has remained as challenge due to its redundancy that involves nonspecific targets. Antisense oligonucleotides primarily work as competitive inhibitors of miRNAs by binding to the mature miRNA strand and inducing degradation or stable duplex formation and making it unavailable for RISC formation. The microRNA-based therapeutic approaches have been recently summarized in several reviews $[8,197,233]$. To minimize the miRNA dysregulation, the low expressed miRNAs could be restored through molecular strategies such as mimic miRNA or adenovirus associated vectors (AAV) carrying miRNA encoding gene. Conversely, the upregulated miRNAs could be optimally managed through usage of antagomirs, locked nucleic acid (LNA) anti-miR, miRNA sponge, and miR-masks. However, the major problems complicating the use of in vivo miRNA therapeutics appear in the phase of tissue-specific delivery or the cellular uptake of sufficient amounts of synthetic oligo to achieve sustained target inhibition [233]. Application of antagomirs/anti-miRs in the animal model has shown few significant promising results $[84,130,184,188]$. For example, Thum et al. demonstrated inhibition of interstitial fibrosis and attenuation of cardiac dysfunction by in vivo silencing of miR-21 through specific antagomir in a mouse pressure-overload-induced disease model with reduced cardiac ERK-MAP (extracellular signalregulated kinase-mitogen-activated protein) kinase activity [184]. In another study, therapeutic inhibition of miR-208a by systemic subcutaneous delivery of LNA-modified oligonucleotide (anti-miR-208a) during hypertension-induced heart failure in rat model demonstrated the potent and sustained silencing of miR-208 in the heart with improved cardiac function and survival [188]. Besides, later on it was demonstrated that treatment with anti-miR-208a can result in significant increase of another miRNA, miR-19b (8.8-fold, $P<0.05)$ in the diseased group [185]. Therefore, more studies are warranted to analyze the impact of anti-miR treatment on the complex miRNA interaction network. Besides the therapeutic demonstration for such molecular approaches in animal models, challenges still remain for its application in humans. Towards this approach, human trials have been ongoing using locked nucleic acid approach and AAV owing to their efficiency and minimal toxicity related to off-target effects [233].

\section{Conclusion}

miRNAs play crucial role in immune system development, maintenance, and function. miRNA dysregulation is implicated in inflammatory pulmonary diseases and cardiac remodeling. Studies of miRNAs role in disease pathomechanisms have been undergoing translation to diagnostic area. In this context, two approaches to exploitation of miRNAs as biomarkers have been emerging: (1) characterization of the miRNA pattern typical for a given disease/condition (i.e., expression profiling) and (2) determination of miRNAs present in body fluids (circulating miRNA), which relative 
stability may add advantage to their potential use as biomarkers.

Regarding potential therapeutic applications of miRNAs, several approaches may be used to control pathological miRNA dysregulation. These range from the inhibition of pathologically upregulated miRNAs by anti-miRNA oligonucleotides/anatagomirs or miRNA mimics to potential delivery of a miRNA to maintain its physiological level in case of its downregulation in a disease. However, development of targeted therapies has remained challenging due to their possibilities of nonspecific targets or alteration in the genemiRNAs and miRNA-miRNA interacting network. Additionally, the epigenetic modifications along with environmental factors as well as mutation within the seed region of miRNA are among the major issues affecting the miRNA based transcriptional control. Therefore, it would be imperative to evaluate the complex regulatory circuit between miRNA, mirSNPs, and epigenetic modifications that modulate the expression of numerous genes in the genome. Additional strategies, such as understanding of genes and the mechanism regulating the miRNAs, are still needed for early detection of disease progression for improving patient outcomes in lung and heart diseases. Taken together, measurement of altered miRNA expression serves as useful noninvasive approach for the diagnosis and prognosis of respiratory and cardiovascular disease. Further, the unique role of miRNAs should be explored for better clinical practices towards disease management.

\section{Conflict of Interests}

The authors declare that there is no conflict of interests regarding the publication of this paper.

\section{Acknowledgments}

This work was supported by IGA_PULF_2013_009, 2014_012; CZ.1.05/2.1.00/01.0030; and CZ.1.07/2.3.00/30.0041. The authors thank Dr. Giovanna Castoldi for helpful advice.

\section{References}

[1] S. Buckingham, "The major world of microRNAs," in Proceedings of the 2nd Horizon Symposium: Understanding the RNAissance, Nature Publishing Group, Scarborough, Me, USA, 2003.

[2] R. C. Lee, R. L. Feinbaum, and V. Ambros, "The C. elegans heterochronic gene lin-4 encodes small RNAs with antisense complementarity to lin-14," Cell, vol. 75, no. 5, pp. 843-854, 1993.

[3] A. E. Pasquinelli, B. J. Reinhart, F. Slack et al., "Conservation of the sequence and temporal expression of let-7 heterochronic regulatory RNA," Nature, vol. 408, no. 6808, pp. 86-89, 2000.

[4] B. J. Reinhart, F. J. Slack, M. Basson et al., "The 21-nucleotide let-7 RNA regulates developmental timing in Caenorhabditis elegans," Nature, vol. 403, no. 6772, pp. 901-906, 2000.

[5] T. Blondal, S. J. Nielsen, A. Baker et al., "Assessing sample and miRNA profile quality in serum and plasma or other biofluids," Methods, vol. 59, no. 1, pp. S1-S6, 2013.
[6] E. P. Murchison and G. J. Hannon, "miRNAs on the move: miRNA biogenesis and the RNAi machinery," Current Opinion in Cell Biology, vol. 16, no. 3, pp. 223-229, 2004.

[7] H. Y. Lee, K. Zhou, A. M. Smith, C. L. Noland, and J. A. Doudna, "Differential roles of human Dicer-binding proteins TRBP and PACT in small RNA processing," Nucleic Acids Research, vol. 41, no. 13, pp. 6568-6576, 2013.

[8] R. Sessa and A. Hata, "Role of microRNAs in lung development and pulmonary diseases," Pulmonary Circulation, vol. 3 , no. 2, pp. 315-328, 2013.

[9] R. M. O’Connell, D. S. Rao, A. A. Chaudhuri, and D. Baltimore, "Physiological and pathological roles for microRNAs in the immune system," Nature Reviews Immunology, vol. 10, no. 2, pp. 111-122, 2010.

[10] J. Yue, "miRNA and vascular cell movement," Advanced Drug Delivery Reviews, vol. 63, no. 8, pp. 616-622, 2011.

[11] Z. Tan, G. Randall, J. Fan et al., "Allele-specific targeting of microRNAs to HLA-G and risk of asthma," American Journal of Human Genetics, vol. 81, no. 4, pp. 829-834, 2007.

[12] X.-W. Su, Y. Yang, M.-L. Lv et al., "Association between singlenucleotide polymorphisms in pre-miRNAs and the risk of asthma in a Chinese population," DNA and Cell Biology, vol. 30, no. 11, pp. 919-923, 2011.

[13] S. Jimenez-Morales, R. Gamboa-Becerra, V. Baca et al., "MiR146a polymorphism is associated with asthma but not with systemic lupus erythematosus and juvenile rheumatoid arthritis in Mexican patients," Tissue Antigens, vol. 80, no. 4, pp. 317-321, 2012.

[14] R. W. Lung, X. Wang, J. Hung-Man et al., "A single nucleotide polymorphism in microRNA-146a is associated with the risk for nasopharyngeal carcinoma," Molecular Carcinogenesis, vol. 52, supplement 1, pp. 28-38, 2013.

[15] J. Nicodemus-Johnson, B. Laxman, R. K. Stern et al., "Maternal asthma and microRNA regulation of soluble HLA-G in the airway," The Journal of Allergy and Clinical Immunology, vol. 131, no. 6, pp. 1496-1503, 2013.

[16] Z. Hu, J. Chen, T. Tian et al., "Genetic variants of miRNA sequences and non-small cell lung cancer survival," The Journal of Clinical Investigation, vol. 118, no. 7, pp. 2600-2608, 2008.

[17] K. A. Yoon, H. Yoon, S. Park et al., "The prognostic impact of microRNA sequence polymorphisms on the recurrence of patients with completely resected non-small cell lung cancer," The Journal of Thoracic and Cardiovascular Surgery, vol. 144, no. 4, pp. 794-807, 2012.

[18] T. Tian, Y. Shu, J. Chen et al., "A functional genetic variant in microRNA-196a2 is associated with increased susceptibility of lung cancer in Chinese," Cancer Epidemiology Biomarkers \& Prevention, vol. 18, no. 4, pp. 1183-1187, 2009.

[19] S. Vinci, S. Gelmini, N. Pratesi et al., "Genetic variants in miR-146a, miR-149, miR-196a2, miR-499 and their influence on relative expression in lung cancers," Clinical Chemistry and Laboratory Medicine, vol. 49, no. 12, pp. 2073-2080, 2011.

[20] J. Wang, Q. Wang, H. Liu et al., "The association of miR146a rs2910164 and miR-196a2 rs11614913 polymorphisms with cancer risk: a meta-analysis of 32 studies," Mutagenesis, vol. 27, no. 6, pp. 779-788, 2012.

[21] Z. Yuan, X. Zeng, D. Yang, W. Wang, and Z. Liu, "Effects of common polymorphism rs11614913 in Hsa-miR-196a2 on lung cancer risk," PLoS ONE, vol. 8, no. 4, article e61047, 2013.

[22] L.-X. Qiu, Y. Wang, Z.-G. Xia et al., "miR-196a2 C allele is a lowpenetrant risk factor for cancer development," Cytokine, vol. 56, no. 3, pp. 589-592, 2011. 
[23] F. Wang, Y.-L. Ma, P. Zhang et al., "A genetic variant in microRNA-196a2 is associated with increased cancer risk: a meta-analysis," Molecular Biology Reports, vol. 39, no. 1, pp. 269275, 2012.

[24] J. Xu, Z. Hu, Z. Xu et al., "Functional variant in microRNA-196a2 contributes to the susceptibility of congenital heart disease in a Chinese population," Human Mutation, vol. 30, no. 8, pp. 12311236, 2009.

[25] L.-J. Li, L.-B. Gao, M.-L. Lv et al., "Association between SNPs in pre-miRNA and risk of chronic obstructive pulmonary disease," Clinical Biochemistry, vol. 44, no. 10-11, pp. 813-816, 2011.

[26] D. Li, T. Wang, X. Song et al., "Genetic study of two single nucleotide polymorphisms within corresponding microRNAs and susceptibility to tuberculosis in a Chinese Tibetan and Han population," Human Immunology, vol. 72, no. 7, pp. 598-602, 2011.

[27] K. D. Taganov, M. P. Boldin, K.-J. Chang, and D. Baltimore, "NF$\kappa \mathrm{B}$-dependent induction of microRNA miR-146, an inhibitor targeted to signaling proteins of innate immune responses," Proceedings of the National Academy of Sciences of the United States of America, vol. 103, no. 33, pp. 12481-12486, 2006.

[28] K. Hikami, A. Kawasaki, I. Ito et al., "Association of a functional polymorphism in the $3^{\prime}$-untranslated region of SPI1 with systemic lupus erythematosus," Arthritis \& Rheumatism, vol. 63, no. 3, pp. 755-763, 2011.

[29] X. Luo, W. Yang, D.-Q. Ye et al., "A functional variant in microRNA-146a promoter modulates its expression and confers disease risk for systemic lupus erythematosus," PLoS Genetics, vol. 7, no. 6, article e1002128, 2011.

[30] R. X. Leng, W. Wang, H. Cen et al., "Gene-gene and gene-sex epistatic interactions of MiR146a, IRF5, IKZF1, ETS1 and IL21 in systemic lupus erythematosus," PLoS ONE, vol. 7, no. 12, article e51090, 2012.

[31] S. E. Lofgren, J. Frostegård, L. Truedsson et al., "Genetic association of miRNA-146a with systemic lupus erythematosus in Europeans through decreased expression of the gene," Genes \& Immunity, vol. 13, no. 3, pp. 268-274, 2012.

[32] Y. Deng, J. Zhao, D. Sakurai et al., "MicroRNA-3148 modulates allelic expression of toll-like receptor 7 variant associated with systemic lupus erythematosus," PLoS Genetics, vol. 9, no. 2, article e1003336, 2013.

[33] F. Amato, M. Seia, S. Giordano et al., "Gene mutation in microRNA target sites of CFTR gene: a novel pathogenetic mechanism in cystic fibrosis?" PLOS ONE, vol. 8, no. 3, article e60448, 2013.

[34] Y. Tang, X. Luo, H. Cui et al., "MicroRNA-146a contributes to abnormal activation of the type I interferon pathway in human lupus by targeting the key signaling proteins," Arthritis \& Rheumatism, vol. 60, no. 4, pp. 1065-1075, 2009.

[35] T. S. Elton, S. E. Sansom, and M. M. Martin, "Cardiovascular disease, single nucleotide polymorphisms, and the renin angiotensin system: is there a microRNA connection?" International Journal of Hypertension, vol. 2010, Article ID 281692, 13 pages, 2010.

[36] P. Sethupathy, C. Borel, M. Gagnebin et al., "Human microRNA155 on chromosome 21 differentially interacts with its polymorphic target in the AGTR1 $3^{\prime}$ untranslated region: a mechanism for functional single-nucleotide polymorphisms related to phenotypes," American Journal of Human Genetics, vol. 81, no. 2, pp. 405-413, 2007.

[37] U. Haas, G. Sczakiel, and S. D. Laufer, "MicroRNA-mediated regulation of gene expression is affected by disease-associated
SNPs within the $3^{\prime}$-UTR via altered RNA structure," RNA Biology, vol. 9, no. 6, pp. 924-937, 2012.

[38] B. Mopidevi, M. Ponnala, and A. Kumar, "Human angiotensinogen $+11525 \mathrm{C} / \mathrm{A}$ polymorphism modulates its gene expression through microRNA binding," Physiological Genomics, vol. 45, no. 19, pp. 901-906, 2013.

[39] C. Wu, Y. Gong, A. Sun et al., “The human MTHFR rs4846049 polymorphism increases coronary heart disease risk through modifying miRNA binding," Nutrition, Metabolism \& Cardiovascular Diseases, vol. 23, no. 7, pp. 693-698, 2013.

[40] S.-L. Ding, J.-X. Wang, J.-Q. Jiao et al., "A pre-microRNA-149 (miR-149) genetic variation affects miR-149 maturation and its ability to regulate the Puma protein in apoptosis," The Journal of Biological Chemistry, vol. 288, no. 37, pp. 26865-26877, 2013.

[41] B. Zhou, L. Rao, Y. Peng et al., "Common genetic polymorphisms in pre-microRNAs were associated with increased risk of dilated cardiomyopathy," Clinica Chimica Acta, vol. 411, no. 17-18, pp. 1287-1290, 2010.

[42] P. Sethupathy, "Illuminating microRNA transcription from the epigenome," Current Genomics, vol. 14, no. 1, pp. 68-77, 2013.

[43] T. A. Volpe, C. Kidner, I. M. Hall, G. Teng, S. I. S. Grewal, and R. A. Martienssen, "Regulation of heterochromatic silencing and histone H3 lysine- 9 methylation by RNAi," Science, vol. 297, no. 5588, pp. 1833-1837, 2002.

[44] C. Baer, R. Claus, and C. Plass, "Genome-wide epigenetic regulation of miRNAs in cancer," Cancer Research, vol. 73, no. 2, pp. 473-477, 2013.

[45] C.-W. Lin, Y.-L. Chang, Y.-C. Chang et al., "MicroRNA-135b promotes lung cancer metastasis by regulating multiple targets in the Hippo pathway and LZTS1," Nature Communications, vol. 4, Article ID 1877, 2013.

[46] M. Fabbri, R. Garzon, A. Cimmino et al., "MicroRNA-29 family reverts aberrant methylation in lung cancer by targeting DNA methyltransferases 3A and 3B," Proceedings of the National Academy of Sciences of the United States of America, vol. 104, no. 40, pp. 15805-15810, 2007.

[47] A. Lujambio and S. W. Lowe, "The microcosmos of cancer," Nature, vol. 482, no. 7385, pp. 347-355, 2012.

[48] B. Brueckner, C. Stresemann, R. Kuner et al., "The human let7a-3 locus contains an epigenetically regulated microRNA gene with oncogenic function," Cancer Research, vol. 67, no. 4, pp. 1419-1423, 2007.

[49] T. Kunej, I. Godnic, J. Ferdin, S. Horvat, P. Dovc, and G. A. Calin, "Epigenetic regulation of microRNAs in cancer: an integrated review of literature," Mutation Research, vol. 717, no. 1-2, pp. 77-84, 2011.

[50] N. Tanaka, S. Toyooka, J. Soh et al., "Frequent methylation and oncogenic role of microRNA-34b/c in small-cell lung cancer," Lung Cancer, vol. 76, no. 1, pp. 32-38, 2012.

[51] D. Lodygin, V. Tarasov, A. Epanchintsev et al., "Inactivation of miR-34a by aberrant CpG methylation in multiple types of cancer," Cell Cycle, vol. 7, no. 16, pp. 2591-2600, 2008.

[52] B. Richardson, "Effect of an inhibitor of DNA methylation on T cells. II. 5-Azacytidine induces self-reactivity in antigen-specific T4 ${ }^{+}$cells," Human Immunology, vol. 17, no. 4, pp. 456-470, 1986.

[53] B. Richardson, L. Scheinbart, J. Strahler, L. Gross, S. Hanash, and M. Johnson, "Evidence for impaired T cell DNA methylation in systemic lupus erythematosus and rheumatoid arthritis," Arthritis \& Rheumatism, vol. 33, no. 11, pp. 1665-1673, 1990.

[54] C. Deng, Q. Lu, Z. Zhang et al., "Hydralazine may induce autoimmunity by inhibiting extracellular signal-regulated 
kinase pathway signaling," Arthritis \& Rheumatism, vol. 48, no. 3, pp. 746-756, 2003.

[55] T. Hughes and A. H. Sawalha, "The role of epigenetic variation in the pathogenesis of systemic lupus erythematosus," Arthritis Research \& Therapy, vol. 13, no. 5, article 245, 2011.

[56] W. Pan, S. Zhu, M. Yuan et al., "MicroRNA-21 and microRNA148 a contribute to DNA hypomethylation in lupus $\mathrm{CD} 4^{+} \mathrm{T}$ cells by directly and indirectly targeting DNA methyltransferase 1 ," The Journal of Immunology, vol. 184, no. 12, pp. 6773-6781, 2010.

[57] S. Zhao, Y. Wang, Y. Liang et al., "MicroRNA-126 regulates DNA methylation in $\mathrm{CD} 4^{+} \mathrm{T}$ cells and contributes to systemic lupus erythematosus by targeting DNA methyltransferase 1," Arthritis \& Rheumatism, vol. 63, no. 5, pp. 1376-1386, 2011.

[58] H. Qin, X. Zhu, J. Liang et al., "MicroRNA-29b contributes to DNA hypomethylation of $\mathrm{CD} 4^{+} \mathrm{T}$ cells in systemic lupus erythematosus by indirectly targeting DNA methyltransferase 1," Journal of Dermatological Science, vol. 69, no. 1, pp. 61-67, 2013.

[59] M. Movassagh, M.-K. Choy, M. Goddard, M. R. Bennett, T. A. Down, and R. S.-Y. Foo, "Differential DNA methylation correlates with differential expression of angiogenic factors in human heart failure," PLoS ONE, vol. 5, no. 1, article e8564, 2010.

[60] S. Udali, P. Guarini, S. Moruzzi, S.-W. Choi, and S. Friso, "Cardiovascular epigenetics: from DNA methylation to microRNAs," Molecular Aspects of Medicine, vol. 34, no. 4, pp. 883-901, 2013.

[61] S. Yang, S. Banerjee, A. de Freitas et al., "Participation of miR200 in pulmonary fibrosis," The American Journal of Pathology, vol. 180, no. 2, pp. 484-493, 2012.

[62] G. Liu, A. Friggeri, Y. Yang et al., "miR-21 mediates fibrogenic activation of pulmonary fibroblasts and lung fibrosis," The Journal of Experimental Medicine, vol. 207, no. 8, pp. 1589-1597, 2010.

[63] L. Honeyman, M. Bazett, T. G. Tomko, and C. K. Haston, "MicroRNA profiling implicates the insulin-like growth factor pathway in bleomycin-induced pulmonary fibrosis in mice," Fibrogenesis \& Tissue Repair, vol. 6, no. 1, article 16, 2013.

[64] P. Li, G.-Q. Zhao, T.-F. Chen et al., "Serum miR-21 and miR155 expression in idiopathic pulmonary fibrosis," The Journal of Asthma, vol. 50, no. 9, pp. 960-964, 2013.

[65] S. Vettori, S. Gay, and O. Distler, "Role of microRNAs in fibrosis," The Open Rheumatology Journal, vol. 6, pp. 130-139, 2012.

[66] T. Sato, X. Liu, A. Nelson et al., "Reduced miR-146a increases prostaglandin $\mathrm{E}_{2}$ in chronic obstructive pulmonary disease fibroblasts," American Journal of Respiratory and Critical Care Medicine, vol. 182, no. 8, pp. 1020-1029, 2010.

[67] E. Tsitsiou, A. E. Williams, S. A. Moschos et al., "Transcriptome analysis shows activation of circulating $\mathrm{CD} 8^{+} \mathrm{T}$ cells in patients with severe asthma," The Journal of Allergy and Clinical Immunology, vol. 129, no. 1, pp. 95-103, 2012.

[68] M. Pinkerton, V. Chinchilli, E. Banta et al., "Differential expression of microRNAs in exhaled breath condensates of patients with asthma, patients with chronic obstructive pulmonary disease, and healthy adults," The Journal of Allergy and Clinical Immunology, vol. 132, no. 1, pp. 217-219, 2013.

[69] Y. Fujita, F. Takeshita, K. Kuwano, and T. Ochiya, "RNAi therapeutic platforms for lung diseases," Pharmaceuticals, vol. 6, no. 2, pp. 223-250, 2013.

[70] T. Tomankova, M. Petrek, and E. Kriegova, "Involvement of microRNAs in physiological and pathological processes in the lung," Respiratory Research, vol. 11, article 159, 2010.
[71] D. Dakhlallah, K. Batte, Y. Wang et al., "Epigenetic regulation of miR-17 92 contributes to the pathogenesis of pulmonary fibrosis," American Journal of Respiratory and Critical Care Medicine, vol. 187, no. 4, pp. 397-405, 2013.

[72] L. Renaud, H. Kasiganesan, E. Gao et al., "Regulation of miR-21 expression by acetylation in myocardial infarction," Circulation Research, vol. 111, no. 4, 2012.

[73] M. Wills-Karp, J. Luyimbazi, X. Xu et al., "Interleukin-13: central mediator of allergic asthma," Science, vol. 282, no. 5397, pp. 2258-2261, 1998.

[74] T. X. Lu and M. E. Rothenberg, "Diagnostic, functional, and therapeutic roles of microRNA in allergic diseases," The Journal of Allergy and Clinical Immunology, vol. 132, no. 1, pp. 3-14, 2013.

[75] J. Mattes, A. Collison, M. Plank, S. Phipps, and P. S. Foster, "Antagonism of microRNA-126 suppresses the effector function of $\mathrm{T}_{\mathrm{H}} 2$ cells and the development of allergic airways disease," Proceedings of the National Academy of Sciences of the United States of America, vol. 106, no. 44, pp. 18704-18709, 2009.

[76] Y. Chiba, M. Tanabe, K. Goto, H. Sakai, and M. Misawa, "Downregulation of miR-133a contributes to up-regulation of RhoA in bronchial smooth muscle cells," American Journal of Respiratory and Critical Care Medicine, vol. 180, no. 8, pp. 713-719, 2009.

[77] B. Levanen, N. R. Bhakta, P. T. Paredes et al., "Altered microRNA profiles in bronchoalveolar lavage fluid exosomes in asthmatic patients," The Journal of Allergy and Clinical Immunology, vol. 131, no. 3, pp. 894-903, 2013.

[78] S. Soeda, J. H. Ohyashiki, K. Ohtsuki, T. Umezu, Y. Setoguchi, and K. Ohyashiki, "Clinical relevance of plasma miR-106b levels in patients with chronic obstructive pulmonary disease," International Journal of Molecular Medicine, vol. 31, no. 3, pp. 533-539, 2013.

[79] P. Leidinger, A. Keller, A. Borries et al., "Specific peripheral miRNA profiles for distinguishing lung cancer from COPD," Lung Cancer, vol. 74, no. 1, pp. 41-47, 2011.

[80] C. Sanfiorenzo, M. I. Ilie, A. Belaid et al., "Two panels of plasma microRNAs as non-invasive biomarkers for prediction of recurrence in resectable NSCLC," PLOS ONE, vol. 8, no. 1, article e54596, 2013.

[81] M. Kumar, T. Ahmad, A. Sharma et al., "Let-7 microRNAmediated regulation of IL-13 and allergic airway inflammation," The Journal of Allergy and Clinical Immunology, vol. 128, no. 5, pp. 1077.e10-1085.e10, 2011.

[82] C. Song, H. Ma, C. Yao, X. Tao, and H. Gan, "Alveolar macrophage-derived vascular endothelial growth factor contributes to allergic airway inflammation in a mouse asthma model," Scandinavian Journal of Immunology, vol. 75, no. 6, pp. 599-605, 2012.

[83] T. X. Lu, A. Munitz, and M. E. Rothenberg, "MicroRNA-21 is up-regulated in allergic airway inflammation and regulates IL12 p35 expression," The Journal of Immunology, vol. 182, no. 8, pp. 4994-5002, 2009.

[84] A. Sharma, M. Kumar, T. Ahmad et al., "Antagonism of mmumir-106a attenuates asthma features in allergic murine model," Journal of Applied Physiology, vol. 113, no. 3, pp. 459-464, 2012.

[85] A. Sharma, M. Kumar, J. Aich et al., "Posttranscriptional regulation of interleukin-10 expression by hsa-miR-106a," Proceedings of the National Academy of Sciences of the United States of America, vol. 106, no. 14, pp. 5761-5766, 2009.

[86] A. Collison, C. Herbert, J. S. Siegle, J. Mattes, P. S. Foster, and R. K. Kumar, "Altered expression of microRNA in the airway wall in chronic asthma: miR-126 as a potential therapeutic target," BMC Pulmonary Medicine, vol. 11, article 29, 2011. 
[87] A. Collison, J. Mattes, M. Plank, and P. S. Foster, "Inhibition of house dust mite-induced allergic airways disease by antagonism of microRNA-145 is comparable to glucocorticoid treatment," The Journal of Allergy and Clinical Immunology, vol. 128, no. 1, pp. 160.e4-167.e4, 2011.

[88] M. J. Feng, F. Shi, C. qiu, and W.-K. Peng, "MicroRNA-181a, $-146 \mathrm{a}$ and $-146 \mathrm{~b}$ in spleen $\mathrm{CD} 4^{+} \mathrm{T}$ lymphocytes play proinflammatory roles in a murine model of asthma," International Immunopharmacology, vol. 13, no. 3, pp. 347-353, 2012.

[89] Y. Zheng, S. Xiong, P. Jiang et al., "Glucocorticoids inhibit lipopolysaccharide-mediated inflammatory response by downregulating microRNA-155: a novel anti-inflammation mechanism," Free Radical Biology and Medicine, vol. 52, no. 8, pp. 13071317, 2012.

[90] R. J. Mayoral, L. Deho, N. Rusca et al., "MiR-221 influences effector functions and actin cytoskeleton in mast cells," PLoS ONE, vol. 6, no. 10, article e26133, 2011.

[91] M. M. Perry, J. E. Baker, D. S. Gibeon, I. M. Adcock, and K. E. Chung, "Airway smooth muscle hyperproliferation is regulated by microRNA-221 in severe asthma," American Journal of Respiratory Cell and Molecular Biology, vol. 50, no. 1, pp. 7-17, 2014.

[92] G. R. Pottelberge, P. Mestdagh, K. R. Bracke et al., "MicroRNA expression in induced sputum of smokers and patients with chronic obstructive pulmonary disease," American Journal of Respiratory and Critical Care Medicine, vol. 183, no. 7, pp. 898906, 2011.

[93] A. Lewis, J. Riddoch-Contreras, S. A. Natanek et al., "Downregulation of the serum response factor/miR-1 axis in the quadriceps of patients with COPD," Thorax, vol. 67, no. 1, pp. 26-34, 2012.

[94] A. Donaldson, S. A. Natanek, A. Lewis et al., "Increased skeletal muscle-specific microRNA in the blood of patients with COPD," Thorax, vol. 68, no. 12, pp. 1140-1149, 2013.

[95] F. Akbas, E. Coskunpinar, E. Aynac1, Y. M. Oltulu, and P. Yildiz, "Analysis of serum micro-RNAs as potential biomarker in chronic obstructive pulmonary disease," Experimental Lung Research, vol. 38, no. 6, pp. 286-294, 2012.

[96] M. E. Ezzie, M. Crawford, J.-H. Cho et al., "Gene expression networks in COPD: microRNA and mRNA regulation," Thorax, vol. 67, no. 2, pp. 122-131, 2012.

[97] F. Schembri, S. Sridhar, C. Perdomo et al., "MicroRNAs as modulators of smoking-induced gene expression changes in human airway epithelium," Proceedings of the National Academy of Sciences of the United States of America, vol. 106, no. 7, pp. 2319-2324, 2009.

[98] F. Hassan, G. J. Nuovo, M. Crawford et al., "MiR-101 and miR144 regulate the expression of the CFTR chloride channel in the lung," PLoS ONE, vol. 7, no. 11, article e50837, 2012.

[99] J. W. Graff, L. S. Powers, A. M. Dickson et al., "Cigarette smoking decreases global microRNA expression in human alveolar macrophages," PLoS ONE, vol. 7, no. 8, article e44066, 2012.

[100] A. E. Gillen, N. Gosalia, S.-H. Leir, and A. Harris, "microRNA regulation of expression of the cystic fibrosis transmembrane conductance regulator gene," The Biochemical Journal, vol. 438, no. 1, pp. 25-32, 2011.

[101] F. Megiorni, S. Cialfi, C. Dominici, S. Quattrucci, and A. Pizzuti, "Synergistic post-transcriptional regulation of the Cystic Fibrosis Transmembrane Conductance Regulator (CFTR) by miR-101 and miR-494 specific binding," PLOS ONE, vol. 6, no. 10, article e26601, 2011.
[102] I. K. Oglesby, I. M. Bray, S. H. Chotirmall et al., "miR-126 is downregulated in cystic fibrosis airway epithelial cells and regulates TOM1 expression," The Journal of Immunology, vol. 184, no. 4, pp. 1702-1709, 2010.

[103] S. Ramachandran, P. H. Karp, P. Jiang et al., "A microRNA network regulates expression and biosynthesis of wild-type and $\Delta$ F508 mutant cystic fibrosis transmembrane conductance regulator," Proceedings of the National Academy of Sciences of the United States of America, vol. 109, no. 33, pp. 13362-13367, 2012.

[104] I. K. Oglesby, S. H. Chotirmall, N. G. McElvaney, and C. M. Greene, "Regulation of cystic fibrosis transmembrane conductance regulator by microRNA-145, -223 , and -494 is altered in $\Delta$ F508 cystic fibrosis airway epithelium," The Journal of Immunology, vol. 190, no. 7, pp. 3354-3362, 2013.

[105] F. Megiorni, S. Cialfi, G. Cimino et al., "Elevated levels of miR145 correlate with SMAD3 down-regulation in Cystic Fibrosis patients," Journal of Cystic Fibrosis, vol. 12, no. 6, pp. 797-802, 2013.

[106] N. Pottier, T. Maurin, B. Chevalier et al., "Identification of keratinocyte growth factor as a target of microRNA-155 in lung fibroblasts: implication in epithelial-mesenchymal interactions," PLoS ONE, vol. 4, no. 8, article e6718, 2009.

[107] S. Bhattacharyya, N. S. Balakathiresan, C. Dalgard et al., "Elevated miR-155 promotes inflammation in cystic fibrosis by driving hyperexpression of interleukin-8," The Journal of Biological Chemistry, vol. 286, no. 13, pp. 11604-11615, 2011.

[108] M. Tsuchiya, P. Kumar, S. Bhattacharyya et al., "Differential regulation of inflammation by inflammatory mediators in cystic fibrosis lung epithelial cells," Journal of Interferon \& Cytokine Research, vol. 33, no. 3, pp. 121-129, 2013.

[109] S. Bhattacharyya, P. Kumar, M. Tsuchiya, A. Bhattacharyya, and R. Biswas, "Regulation of miR-155 biogenesis in cystic fibrosis lung epithelial cells: antagonistic role of two mRNAdestabilizing proteins, KSRP and TTP," Biochemical and Biophysical Research Communications, vol. 433, no. 4, pp. 484-488, 2013.

[110] S. Ramachandran, P. H. Karp, S. R. Osterhaus et al., "Posttranscriptional regulation of cystic fibrosis transmembrane conductance regulator expression and function by microRNAs," American Journal of Respiratory Cell and Molecular Biology, vol. 49, no. 4, pp. 544-551, 2013.

[111] K. V. Pandit, D. Corcoran, H. Yousef et al., "Inhibition and role of let-7d in idiopathic pulmonary fibrosis," American Journal of Respiratory and Critical Care Medicine, vol. 182, no. 2, pp. 220229, 2010.

[112] S. R. Oak, L. Murray, A. Herath et al., "A microRNA processing defect in rapidly progressing idiopathic pulmonary fibrosis," PLoS ONE, vol. 6, no. 6, article e21253, 2011.

[113] D. Dakhlallah, Cross-talk between epigenetic regulation and Mir-17 92 cluster expression in idiopathic pulmonary fibrosis (IPF) [Ph.D. dissertation], The Ohio State University, Columbus, Ohio, USA, 2011.

[114] M. Yamada, H. Kubo, C. Ota et al., "The increase of microRNA21 during lung fibrosis and its contribution to epithelialmesenchymal transition in pulmonary epithelial cells," Respiratory Research, vol. 14, no. 1, article 95, 2013.

[115] L. Cushing, P. P. Kuang, J. Qian et al., "miR-29 is a major regulator of genes associated with pulmonary fibrosis," American Journal of Respiratory Cell and Molecular Biology, vol. 45, no. 2, pp. 287-294, 2011. 
[116] K. V. Pandit, J. Milosevic, and N. Kaminski, "MicroRNAs in idiopathic pulmonary fibrosis," Translational Research, vol. 157, no. 4, pp. 191-199, 2011.

[117] J. Xiao, X.-M. Meng, X. R. Huang et al., "miR-29 inhibits bleomycin-induced pulmonary fibrosis in mice," Molecular Therapy, vol. 20, no. 6, pp. 1251-1260, 2012.

[118] J. Milosevic, K. Pandit, M. Magister et al., "Profibrotic role of miR-154 in pulmonary fibrosis," American Journal of Respiratory Cell and Molecular Biology, vol. 47, no. 6, pp. 879-887, 2012.

[119] T. Xie, J. Liang, N. Liu et al., "MicroRNA-127 inhibits lung inflammation by targeting IgG Fc $\gamma$ receptor I," The Journal of Immunology, vol. 188, no. 5, pp. 2437-2444, 2012.

[120] K. Vaporidi, E. Vergadi, E. Kaniaris et al., "Pulmonary microRNA profiling in a mouse model of ventilator-induced lung injury," American Journal of Physiology: Lung Cellular and Molecular Physiology, vol. 303, no. 3, pp. L199-L207, 2012.

[121] N. Yehya, A. Yerrapureddy, J. Tobias, and S. S. Margulies, "MicroRNA modulate alveolar epithelial response to cyclic stretch," BMC Genomics, vol. 13, article 154, 2012.

[122] Z. Zeng, H. Gong, Y. Li et al., "Upregulation of miR-146a contributes to the suppression of inflammatory responses in LPS-induced acute lung injury," Experimental Lung Research, vol. 39, no. 7, pp. 275-282, 2013.

[123] M. M. Perry, S. A. Moschos, A. E. Williams, N. J. Shepherd, H. M. Larner-Svensson, and M. A. Lindsay, "Rapid changes in microRNA-146a expression negatively regulate the IL-1 $\beta$ induced inflammatory response in human lung alveolar epithelial cells1," The Journal of Immunology, vol. 180, no. 8, pp. 5689$5698,2008$.

[124] X. Sun, B. Icli, A. K. Wara et al., "MicroRNA-181b regulates NF$\kappa \mathrm{B}$-mediated vascular inflammation," The Journal of Clinical Investigation, vol. 122, no. 6, pp. 1973-1990, 2012.

[125] M. Brock, M. Trenkmann, R. E. Gay et al., "Interleukin-6 modulates the expression of the bone morphogenic protein receptor type II through a novel STAT3-microRNA cluster 17/92 pathway," Circulation Research, vol. 104, no. 10, pp. 1184-1191, 2009.

[126] J. Sarkar, D. Gou, P. Turaka, E. Viktorova, R. Ramchandran, and J. U. Raj, "MicroRNA-21 plays a role in hypoxia-mediated pulmonary artery smooth muscle cell proliferation and migration," American Journal of Physiology: Lung Cellular and Molecular Physiology, vol. 299, no. 6, pp. L861-L871, 2010.

[127] S. Yang, S. Banerjee, A. de Freitas et al., "miR-21 regulates chronic hypoxia-induced pulmonary vascular remodeling," American Journal of Physiology: Lung Cellular and Molecular Physiology, vol. 302, no. 6, pp. L521-L529, 2012.

[128] C. Y. Wei, H. Henderson, C. Spradley et al., "Circulating miRNAs as potential marker for pulmonary hypertension," PLoS ONE, vol. 8, no. 5, article e64396, 2013.

[129] K. Kang, X. Peng, X. Zhang et al., "MicroRNA-124 suppresses the transactivation of nuclear factor of activated $\mathrm{T}$ cells by targeting multiple genes and inhibits the proliferation of pulmonary artery smooth muscle cells," The Journal of Biological Chemistry, vol. 288, no. 35, pp. 25414-25427, 2013.

[130] P. Caruso, Y. Dempsie, H. C. Stevens et al., "A role for miR-145 in pulmonary arterial hypertension: evidence from mouse models and patient samples," Circulation Research, vol. 111, no. 3, pp. 290-300, 2012.

[131] A. Courboulin, R. Paulin, N. J. Giguère et al., "Role for miR204 in human pulmonary arterial hypertension," Journal of Experimental Medicine, vol. 208, no. 3, pp. 535-548, 2011.
[132] S. Jalali, G. K. Ramanathan, P. T. Parthasarathy et al., "Mir-206 regulates pulmonary artery smooth muscle cell proliferation and differentiation," PLOS ONE, vol. 7, no. 10, article e46808, 2012.

[133] J. Yue, J. Guan, X. Wang et al., "MicroRNA-206 is involved in hypoxia-induced pulmonary hypertension through targeting of the HIF-1 $\alpha$ /Fhl-1 pathway," Laboratory Investigation, vol. 93, no. 7, pp. 748-759, 2013.

[134] J. Kim, Y. Kang, Y. Kojima et al., "An endothelial apelin-FGF link mediated by miR-424 and miR-503 is disrupted in pulmonary arterial hypertension," Nature Medicine, vol. 19, no. 1, pp. 74-82, 2013.

[135] G. Raghu, H. R. Collard, J. J. Egan et al., "An official ATS/ERS/JRS/ALAT statement: idiopathic pulmonary fibrosis: evidence-based guidelines for diagnosis and management," American Journal of Respiratory and Critical Care Medicine, vol. 183, no. 6, pp. 788-824, 2011.

[136] T. Yang, G.-F. Zhang, X.-F. Chen et al., "MicroRNA-214 provokes cardiac hypertrophy via repression of EZH2," Biochemical and Biophysical Research Communications, vol. 436, no. 4, pp. 578-584, 2013.

[137] E. Orenes-Pinero, S. Montoro-García, J. V. Patel, M. Valdés, F. Marín, and G. Y. Lip, "Role of microRNAs in cardiac remodelling: new insights and future perspectives," International Journal of Cardiology, vol. 167, no. 5, pp. 1651-1659, 2013.

[138] G. Condorelli, M. V. Latronico, and E. Cavarretta, "microRNAs in cardiovascular diseases: current knowledge and the road ahead," Journal of the American College of Cardiology, 2014.

[139] P. Libby, "Inflammation and cardiovascular disease mechanisms," The American Journal of Clinical Nutrition, vol. 83, no. 2, pp. 456S-460S, 2006.

[140] L. Xiao, Y. Liu, and N. Wang, "New paradigms in inflammatory signaling in vascular endothelial cells," American Journal of Physiology: Heart and Circulatory Physiology, 2013.

[141] J. Bauersachs and T. Thum, "Biogenesis and regulation of cardiovascular microRNAs," Circulation Research, vol. 109, no. 3, pp. 334-347, 2011.

[142] R. Ranjha and J. Paul, "Micro-RNAs in inflammatory diseases and as a link between inflammation and cancer," Inflammation Research, vol. 62, no. 4, pp. 343-355, 2013.

[143] E. Raitoharju, L.-P. Lyytikäinen, M. Levula et al., "miR21, miR-210, miR-34a, and miR-146a/b are up-regulated in human atherosclerotic plaques in the Tampere Vascular Study," Atherosclerosis, vol. 219, no. 1, pp. 211-217, 2011.

[144] K. Bidzhekov, L. Gan, B. Denecke et al., "microRNA expression signatures and parallels between monocyte subsets and atherosclerotic plaque in humans," Thrombosis and Haemostasis, vol. 107, no. 4, pp. 619-625, 2012.

[145] K.-C. Chen, Y.-C. Liao, I.-C. Hsieh, Y.-S. Wang, C.-Y. Hu, and S.-H. H. Juo, "OxLDL causes both epigenetic modification and signaling regulation on the microRNA-29b gene: novel mechanisms for cardiovascular diseases," Journal of Molecular and Cellular Cardiology, vol. 52, no. 3, pp. 587-595, 2012.

[146] X. Sun, S. He, A. K. Wara et al., "Systemic delivery of microRNA$181 b$ inhibits nuclear factor- $\kappa \mathrm{B}$ activation, vascular inflammation, and atherosclerosis in apolipoprotein E-deficient mice," Circulation Research, vol. 114, no. 1, pp. 32-40, 2014.

[147] D. J. Son, S. Kumar, W. Takabe et al., "The atypical mechanosensitive microRNA-712 derived from pre-ribosomal RNA induces endothelial inflammation and atherosclerosis," Nature Communications, vol. 4, Article ID 3000, 2013. 
[148] G. Long, F. Wang, Q. Duan et al., "Circulating miR-30a, miR-195 and let-7b associated with acute myocardial infarction," PLoS ONE, vol. 7, no. 12, article e50926, 2012.

[149] J. Ai, R. Zhang, Y. Li et al., "Circulating microRNA-1 as a potential novel biomarker for acute myocardial infarction," Biochemical and Biophysical Research Communications, vol. 391, no. 1, pp. 73-77, 2010.

[150] S. Dimmeler and A. M. Zeiher, "Circulating microRNAs: novel biomarkers for cardiovascular diseases?" European Heart Journal, vol. 31, no. 22, pp. 2705-2707, 2010.

[151] S. K. Gupta, C. Bang, and T. Thum, "Circulating microRNAs as biomarkers and potential paracrine mediators of cardiovascular disease," Circulation: Cardiovascular Genetics, vol. 3, no. 5, pp. 484-488, 2010.

[152] Y. Cheng, N. Tan, J. Yang et al., "A translational study of circulating cell-free microRNA-1 in acute myocardial infarction," Clinical Science, vol. 119, no. 2, pp. 87-95, 2010.

[153] G. Long, F. Wang, Q. Duan et al., "Human circulating microRNA-1 and microRNA-126 as potential novel indicators for acute myocardial infarction," International Journal of Biological Sciences, vol. 8, no. 6, pp. 811-818, 2012.

[154] G.-K. Wang, J.-Q. Zhu, J.-T. Zhang et al., "Circulating microRNA: a novel potential biomarker for early diagnosis of acute myocardial infarction in humans," European Heart Journal, vol. 31, no. 6, pp. 659-666, 2010.

[155] S. Dong, Y. Cheng, J. Yang et al., "MicroRNA expression signature and the role of microRNA-21 in the early phase of acute myocardial infarction," The Journal of Biological Chemistry, vol. 284, no. 43, pp. 29514-29525, 2009.

[156] Y. D’Alessandra, P. Devanna, F. Limana et al., "Circulating microRNAs are new and sensitive biomarkers of myocardial infarction," European Heart Journal, vol. 31, no. 22, pp. 27652773, 2010.

[157] R. Wang, N. Li, Y. Zhang, Y. Ran, and J. Pu, "Circulating microRNAs are promising novel biomarkers of acute myocardial infarction," Internal Medicine, vol. 50, no. 17, pp. 1789-1795, 2011.

[158] A. J. Tijsen, Y. M. Pinto, and E. E. Creemers, "Non-cardiomyocyte microRNAs in heart failure," Cardiovascular Research, vol. 93, no. 4, pp. 573-582, 2012.

[159] M. F. Corsten, R. Dennert, S. Jochems et al., "Circulating MicroRNA-208b and MicroRNA-499 reflect myocardial damage in cardiovascular disease," Circulation: Cardiovascular Genetics, vol. 3, no. 6, pp. 499-506, 2010.

[160] T. Adachi, M. Nakanishi, Y. Otsuka et al., "Plasma microRNA 499 as a biomarker of acute myocardial infarction," Clinical Chemistry, vol. 56, no. 7, pp. 1183-1185, 2010.

[161] Q. Li, X.-W. Song, J. Zou et al., "Attenuation of microRNA-1 derepresses the cytoskeleton regulatory protein twinfilin-1 to provoke cardiac hypertrophy," Journal of Cell Science, vol. 123, part 14, pp. 2444-2452, 2010.

[162] Y. Cheng, R. Ji, J. Yue et al., "MicroRNAs are aberrantly expressed in hypertrophic heart: do they play a pole in cardiac hypertrophy?" The American Journal of Pathology, vol. 170, no. 6, pp. 1831-1840, 2007.

[163] Z. P. Huang, J. Chen, H. Y. Seok et al., "MicroRNA-22 regulates cardiac hypertrophy and remodeling in response to stress," Circulation Research, vol. 112, no. 9, pp. 1234-1243, 2013.

[164] J. Wang, Y. Song, Y. Zhang et al., "Cardiomyocyte overexpression of miR-27b induces cardiac hypertrophy and dysfunction in mice," Cell Research, vol. 22, no. 3, pp. 516-527, 2012.
[165] R. Roncarati, C. V. Anselmi, M. A. Losi et al., "Circulating miR-29a, among other up-regulated microRNAs, is the only biomarker for both hypertrophy and fibrosis in patients with hypertrophic cardiomyopathy," Journal of the American College of Cardiology, vol. 63, no. 9, pp. 920-927, 2014.

[166] W. Pan, Y. Zhong, C. Cheng et al., "MiR-30-regulated autophagy mediates angiotensin II-induced myocardial hypertrophy," PLoS ONE, vol. 8, no. 1, article e53950, 2013.

[167] A. Care, D. Catalucci, F. Felicetti et al., "MicroRNA-133 controls cardiac hypertrophy," Nature Medicine, vol. 13, no. 5, pp. 613618, 2007.

[168] D.-L. Dong, C. Chen, R. Huo et al., "Reciprocal repression between microRNA-133 and calcineurin regulates cardiac hypertrophy: a novel mechanism for progressive cardiac hypertrophy," Hypertension, vol. 55, no. 4, pp. 946-952, 2010.

[169] S. Heymans, M. E. Corsten, W. Verhesen et al., "Macrophage microRNA-155 promotes cardiac hypertrophy and failure," Circulation, vol. 128, no. 13, pp. 1420-1432, 2013.

[170] E. M. Small, R. J. A. Frost, and E. N. Olson, "MicroRNAs add a new dimension to cardiovascular disease," Circulation, vol. 121, no. 8, pp. 1022-1032, 2010.

[171] D. Sayed, M. He, Z. Yang, and M. Abdellatif, "MicroRNA21 enhances AKT activity and reduces myocyte apoptosis and ischemic heart failure through suppression of PTEN," Circulation, vol. 120, no. 18, article S838, 2009.

[172] Y. Tu, L. Wan, Y. Fan et al., "Ischemic postconditioningmediated miRNA-21 protects against cardiac ischemia/reperfusion injury via PTEN/Akt pathway," PLoS ONE, vol. 8, no. 10, article e75872, 2013.

[173] K. Kin, S. Miyagawa, S. Fukushima et al., "Tissue- and plasmaspecific MicroRNA signatures for atherosclerotic abdominal aortic aneurysm," Journal of the American Heart Association, vol. 1, no. 5, Article ID e000745, 2012.

[174] G. Castoldi, C. R. T. di Gioia, C. Bombardi et al., "MiR-133a regulates collagen 1A1: potential role of miR-133a in myocardial fibrosis in angiotensin II-dependent hypertension," Journal of Cellular Physiology, vol. 227, no. 2, pp. 850-856, 2012.

[175] C. Wei, I. K. Kim, S. Kumar et al., "NF- $\kappa$ B mediated miR-26a regulation in cardiac fibrosis," Journal of Cellular Physiology, vol. 228, no. 7, pp. 1433-1442, 2013.

[176] R. F. Duisters, A. J. Tijsen, B. Schroen et al., "miR-133 and miR30 regulate connective tissue growth factor: implications for a role of micrornas in myocardial matrix remodeling," Circulation Research, vol. 104, no. 2, pp. 170-178, 2009.

[177] J. Beaumont, B. López, N. Hermida et al., "microRNA-122 down-regulation may play a role in severe myocardial fibrosis in human aortic stenosis through TGF- $\beta 1$ up-regulation," Clinical Science, vol. 126, no. 7, pp. 497-506, 2014.

[178] S. Fichtlscherer, S. de Rosa, H. Fox et al., "Circulating microRNAs in patients with coronary artery disease," Circulation Research, vol. 107, no. 5, pp. 677-684, 2010.

[179] V. P. van Empel, L. J. de Windt, and P. A. da Costa Martins, "Circulating miRNAs: reflecting or affecting cardiovascular disease?" Current Hypertension Reports, vol. 14, no. 6, pp. 498509, 2012.

[180] J. Ren, J. Zhang, N. Xu et al., "Signature of circulating microRNAs as potential biomarkers in vulnerable coronary artery disease," PLoS ONE, vol. 8, no. 12, article e80738, 2013.

[181] M. Hoekstra, C. A. C. van der Lans, B. Halvorsen et al., "The peripheral blood mononuclear cell microRNA signature of coronary artery disease," Biochemical and Biophysical Research Communications, vol. 394, no. 3, pp. 792-797, 2010. 
[182] S. Ikeda and W. T. Pu, "Expression and function of microRNAs in heart disease," Current Drug Targets, vol. 11, no. 8, pp. 913925, 2010.

[183] S. Roy, S. Khanna, S.-R. A. Hussain et al., "MicroRNA expression in response to murine myocardial infarction: miR-21 regulates fibroblast metalloprotease- 2 via phosphatase and tensin homologue," Cardiovascular Research, vol. 82, no. 1, pp. 21-29, 2009.

[184] T. Thum, C. Gross, J. Fiedler et al., "MicroRNA-21 contributes to myocardial disease by stimulating MAP kinase signalling in fibroblasts," Nature, vol. 456, no. 7224, pp. 980-984, 2008.

[185] B. A. Dickinson, H. M. Semus, R. L. Montgomery et al., "Plasma microRNAs serve as biomarkers of therapeutic efficacy and disease progression in hypertension-induced heart failure," European Journal of Heart Failure, vol. 15, no. 6, pp. 650-659, 2013.

[186] Y. Fukushima, M. Nakanishi, H. Nonogi, Y. Goto, and N. Iwai, "Assessment of plasma miRNAs in congestive heart failure," Circulation Journal, vol. 75, no. 2, pp. 336-340, 2011.

[187] N. Danowski, I. Manthey, H. G. Jakob, W. Siffert, J. Peters, and U. H. Frey, "Decreased expression of miR-133a but not of miR-1 is associated with signs of heart failure in patients undergoing coronary bypass surgery," Cardiology, vol. 125, no. 2, pp. 125-130, 2013.

[188] R. L. Montgomery, T. G. Hullinger, H. M. Semus et al., "Therapeutic inhibition of miR-208a improves cardiac function and survival during heart failure," Circulation, vol. 124, no. 14, pp. 1537-1547, 2011.

[189] K. Endo, Y. Naito, X. Ji et al., "MicroRNA 210 as a biomarker for congestive heart failure," Biological \& Pharmaceutical Bulletin, vol. 36, no. 1, pp. 48-54, 2013.

[190] K. L. Fan, H. F. Zhang, J. Shen, Q. Zhang, and X. L. Li, "Circulating microRNAs levels in Chinese heart failure patients caused by dilated cardiomyopathy," Indian Heart Journal, vol. 65, no. 1, pp. 12-16, 2013.

[191] A. J. Tijsen, E. E. Creemers, P. D. Moerland et al., "MiR423-5p as a circulating biomarker for heart failure," Circulation Research, vol. 106, no. 6, pp. 1035-1039, 2010.

[192] Y. Goren, M. Kushnir, B. Zafrir, S. Tabak, B. S. Lewis, and O. Amir, "Serum levels of microRNAs in patients with heart failure," European Journal of Heart Failure, vol. 14, no. 2, pp. 147154, 2012.

[193] E. E. Creemers, A. J. Tijsen, and Y. M. Pinto, "Circulating microRNAs: novel biomarkers and extracellular communicators in cardiovascular disease?" Circulation Research, vol. 110, no. 3, pp. 483-495, 2012.

[194] V. Kinet, J. Halkein, E. Dirkx, and L. J. de Windt, "Cardiovascular extracellular microRNAs: emerging diagnostic markers and mechanisms of cell-to-cell RNA communication," Frontiers in Genetics, vol. 4, article 214, 2013.

[195] A. J. Tijsen, Y. M. Pinto, and E. E. Creemers, "Circulating microRNAs as diagnostic biomarkers for cardiovascular diseases," American Journal of Physiology: Heart and Circulatory Physiology, vol. 303, no. 9, pp. H1085-H1095, 2012.

[196] E. M. Small and E. N. Olson, "Pervasive roles of microRNAs in cardiovascular biology," Nature, vol. 469, no. 7330, pp. 336-342, 2011.

[197] E. van Rooij and E. N. Olson, "MicroRNA therapeutics for cardiovascular disease: opportunities and obstacles," Nature Reviews: Drug Discovery, vol. 11, no. 11, pp. 860-872, 2012.
[198] Y. Kuwabara, K. Ono, T. Horie et al., "Increased microRNA1 and microRNA-133a levels in serum of patients with cardiovascular disease indicate myocardial damage," Circulation: Cardiovascular Genetics, vol. 4, no. 4, pp. 446-454, 2011.

[199] I. P. Tereshchenko, J. Petrkova, M. I. Voevoda et al., "CCL5/RANTES gene polymorphisms in Slavonic patients with myocardial infarction," Mediators of Inflammation, vol. 2011, Article ID 525691, 6 pages, 2011.

[200] M. Nazari-Jahantigh, Y. Wei, H. Noels et al., "MicroRNA-155 promotes atherosclerosis by repressing Bcl6 in macrophages," The Journal of Clinical Investigation, vol. 122, no. 11, pp. 41904202, 2012.

[201] W.-J. Chen, K. Yin, G.-J. Zhao, Y.-C. Fu, and C.-K. Tang, "The magic and mystery of MicroRNA-27 in atherosclerosis," Atherosclerosis, vol. 222, no. 2, pp. 314-323, 2012.

[202] Y. Wei, M. Nazari-Jahantigh, L. Chan et al., “The microRNA$342-5 p$ fosters inflammatory macrophage activation through an Akt1- and microRNA-155-dependent pathway during atherosclerosis," Circulation, vol. 127, no. 15, pp. 1609-1619, 2013.

[203] J. Zhu, T. Chen, Z. Li et al., "Regulation of microRNA155 in atherosclerotic inflammatory responses by targeting MAP3K10," PLoS ONE, vol. 7, no. 11, article e46551, 2012.

[204] Y. Wei, M. Nazari-Jahantigh, P. Neth, C. Weber, and A. Schober, "MicroRNA-126, -145, and -155: a therapeutic triad in atherosclerosis?" Arteriosclerosis, Thrombosis, and Vascular Biology, vol. 33, no. 3, pp. 449-454, 2013.

[205] A. B. Aurora, A. I. Mahmoud, X. Luo et al., "MicroRNA-214 protects the mouse heart from ischemic injury by controlling $\mathrm{Ca}^{2+}$ overload and cell death," The Journal of Clinical Investigation, vol. 122, no. 4, pp. 1222-1232, 2012.

[206] G. Vassalli and B. R. Winkelmann, "Molecular genetics of myocardial infarction: many genes, more questions than answers," European Heart Journal, vol. 25, no. 6, pp. 451-453, 2004.

[207] C. Li, F. Pei, X. Zhu, D. D. Duan, and C. Zeng, "Circulating microRNAs as novel and sensitive biomarkers of acute myocardial Infarction," Clinical Biochemistry, vol. 45, no. 10-11, pp. 727732, 2012.

[208] M. V. Latronico and G. Condorelli, "microRNAs in hypertrophy and heart failure," Experimental Biology and Medicine, vol. 236, no. 2, pp. 125-131, 2011.

[209] M. Abdellatif, "The role of microRNA-133 in cardiac hypertrophy uncovered," Circulation Research, vol. 106, no. 1, pp. 16-18, 2010.

[210] E. van Rooij, L. B. Sutherland, J. E. Thatcher et al., "Dysregulation of microRNAs after myocardial infarction reveals a role of miR-29 in cardiac fibrosis," Proceedings of the National Academy of Sciences of the United States of America, vol. 105, no. 35, pp. 13027-13032, 2008.

[211] Y. Cheng and C. Zhang, "MicroRNA-21 in cardiovascular disease," Journal of Cardiovascular Translational Research, vol. 3, no. 3, pp. 251-255, 2010.

[212] H. Zhu and G.-C. Fan, "Role of microRNAs in the reperfused myocardium towards post-infarct remodelling," Cardiovascular Research, vol. 94, no. 2, pp. 284-292, 2012.

[213] A. Banerjee and K. Luettich, "MicroRNAs as potential biomarkers of smoking-related diseases," Biomarkers in Medicine, vol. 6, no. 5, pp. 671-684, 2012.

[214] X. Chen, Y. Ba, L. Ma et al., "Characterization of microRNAs in serum: a novel class of biomarkers for diagnosis of cancer and other diseases," Cell Research, vol. 18, no. 10, pp. 997-1006, 2008. 
[215] P. S. Mitchell, R. K. Parkin, E. M. Kroh et al., "Circulating microRNAs as stable blood-based markers for cancer detection," Proceedings of the National Academy of Sciences of the United States of America, vol. 105, no. 30, pp. 10513-10518, 2008.

[216] A. Etheridge, I. Lee, L. Hood, D. Galas, and K. Wang, "Extracellular microRNA: a new source of biomarkers," Mutation Research, vol. 717, no. 1-2, pp. 85-90, 2011.

[217] J. D. Arroyo, J. R. Chevillet, E. M. Kroh et al., "Argonaute2 complexes carry a population of circulating microRNAs independent of vesicles in human plasma," Proceedings of the National Academy of Sciences of the United States of America, vol. 108, no. 12, pp. 5003-5008, 2011.

[218] P. Diehl, A. Fricke, L. Sander et al., "Microparticles: major transport vehicles for distinct microRNAs in circulation," Cardiovascular Research, vol. 93, no. 4, pp. 633-644, 2012.

[219] R. A. Boon and K. C. Vickers, "Intercellular transport of microRNAs," Arteriosclerosis, Thrombosis, and Vascular Biology, vol. 33, no. 2, pp. 186-192, 2013.

[220] H. H. Cheng, H. S. Yi, Y. Kim et al., "Plasma processing conditions substantially influence circulating microRNA biomarker levels," PLoS ONE, vol. 8, no. 6, article e64795, 2013.

[221] K. Wang, Y. Yuan, J.-H. Cho, S. McClarty, D. Baxter, and D. J. Galas, "Comparing the MicroRNA spectrum between serum and plasma," PLoS ONE, vol. 7, no. 7, article e41561, 2012.

[222] J. A. Weber, D. H. Baxter, S. Zhang et al., "The microRNA spectrum in 12 body fluids," Clinical Chemistry, vol. 56, no. 11, pp. 1733-1741, 2010.

[223] S. de Rosa, S. Fichtlscherer, R. Lehmann, B. Assmus, S. Dimmeler, and A. M. Zeiher, "Transcoronary concentration gradients of circulating MicroRNAs," Circulation, vol. 124, no. 18, pp. 1936-1944, 2011.

[224] P. Willeit, A. Zampetaki, K. Dudek et al., "Circulating microRNAs as novel biomarkers for platelet activation," Circulation Research, vol. 112, no. 4, pp. 595-600, 2013.

[225] C. C. Pritchard, H. H. Cheng, and M. Tewari, "MicroRNA profiling: approaches and considerations," Nature Reviews Genetics, vol. 13, no. 5, pp. 358-369, 2012.

[226] Y. Huang, Q. Zou, S. P. Wang, S. M. Tang, G. Z. Zhang, and X. J. Shen, "The discovery approaches and detection methods of microRNAs," Molecular Biology Reports, vol. 38, no. 6, pp. 41254135, 2011.

[227] F. Russo, S. di Bella, G. Nigita et al., "miRandola: extracellular circulating microRNAs database," PLoS ONE, vol. 7, no. 10, article e47786, 2012.

[228] M. J. Lodes, M. Caraballo, D. Suciu, S. Munro, A. Kumar, and B. Anderson, "Detection of cancer with serum miRNAs on an oligonucleotide microarray," PLoS ONE, vol. 4, no. 7, article e6229, 2009.

[229] C. Chen, D. A. Ridzon, A. J. Broomer et al., "Real-time quantification of microRNAs by stem-loop RT-PCR," Nucleic Acids Research, vol. 33, no. 20, article e179, 2005.

[230] H.-J. Fu, J. Zhu, M. Yang et al., "A novel method to monitor the expression of microRNAs," Molecular Biotechnology, vol. 32, no. 3, pp. 197-204, 2006.

[231] H. J. Peltier and G. J. Latham, "Normalization of microRNA expression levels in quantitative RT-PCR assays: identification of suitable reference RNA targets in normal and cancerous human solid tissues," RNA, vol. 14, no. 5, pp. 844-852, 2008.

[232] P. Mestdagh, P. van Vlierberghe, A. de Weer et al., "A novel and universal method for microRNA RT-qPCR data normalization," Genome Biology, vol. 10, no. 6, article R64, 2009.
[233] R. Garzon, G. Marcucci, and C. M. Croce, "Targeting microRNAs in cancer: rationale, strategies and challenges," Nature Reviews: Drug Discovery, vol. 9, no. 10, pp. 775-789, 2010. 


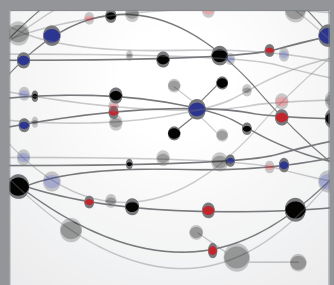

The Scientific World Journal
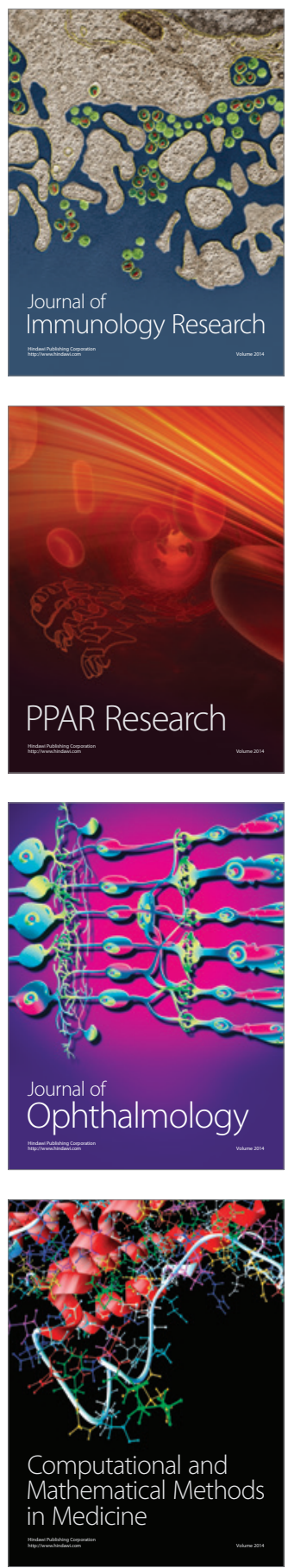

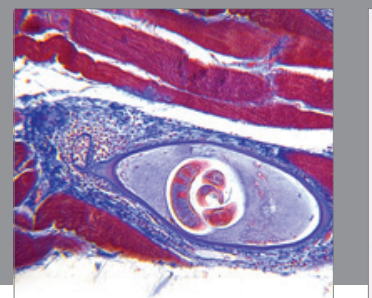

Gastroenterology

Research and Practice
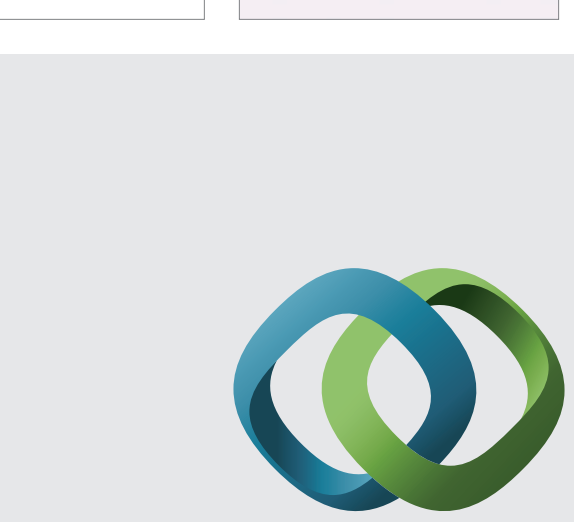

\section{Hindawi}

Submit your manuscripts at

http://www.hindawi.com
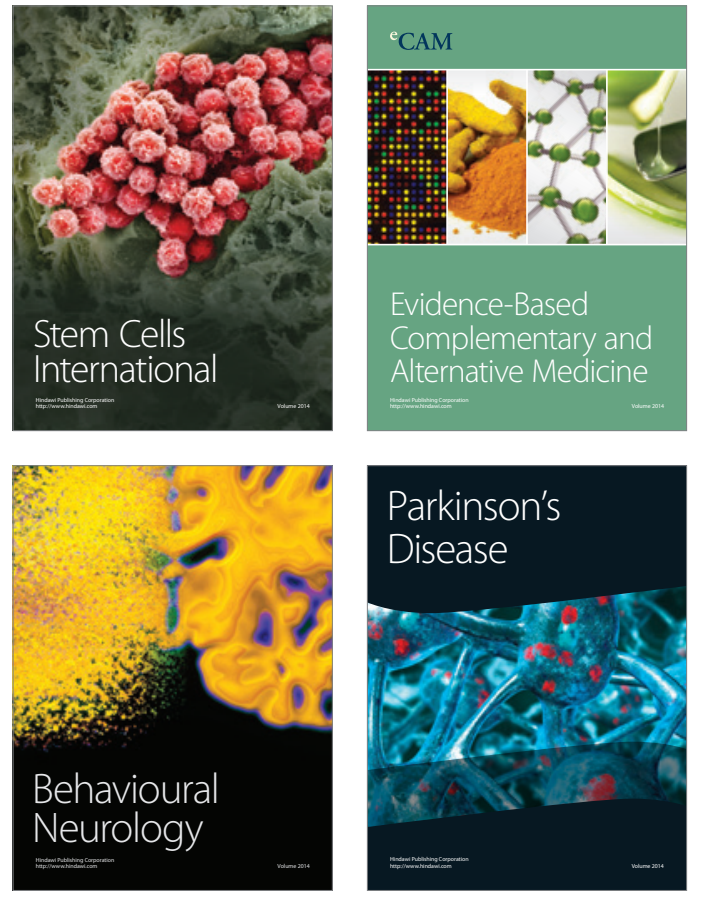
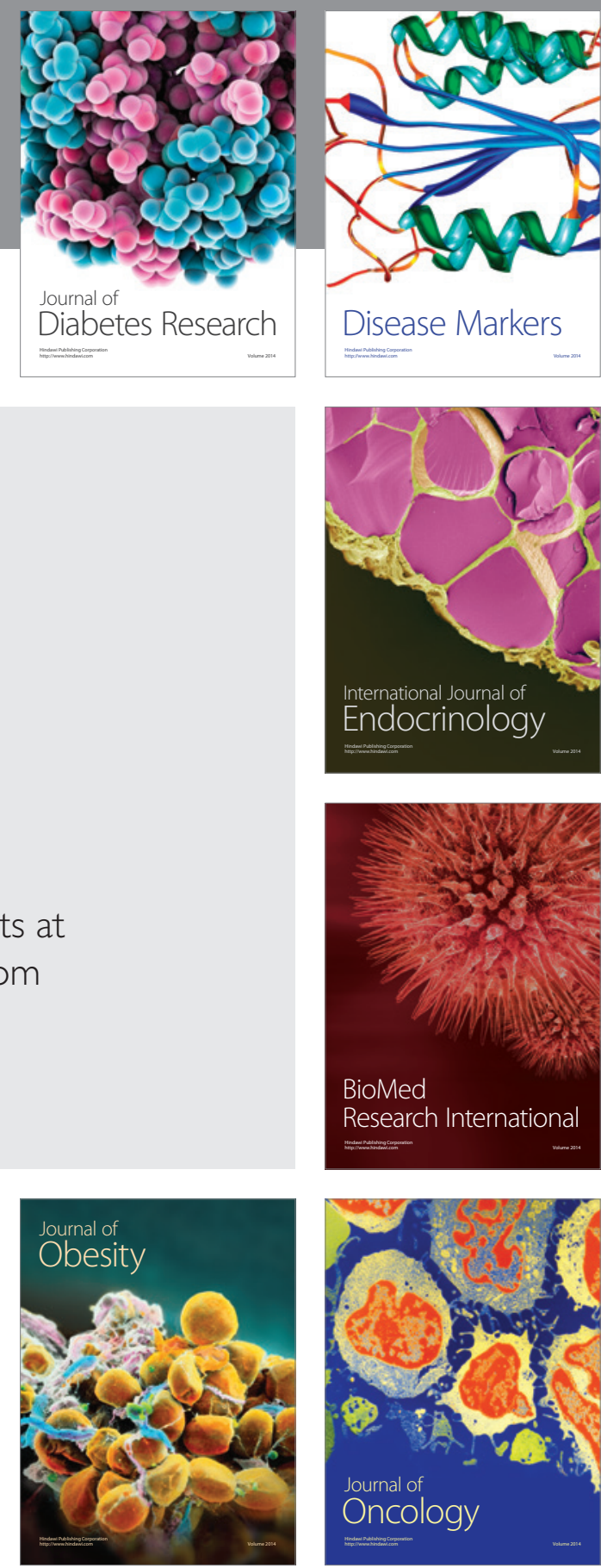

Disease Markers
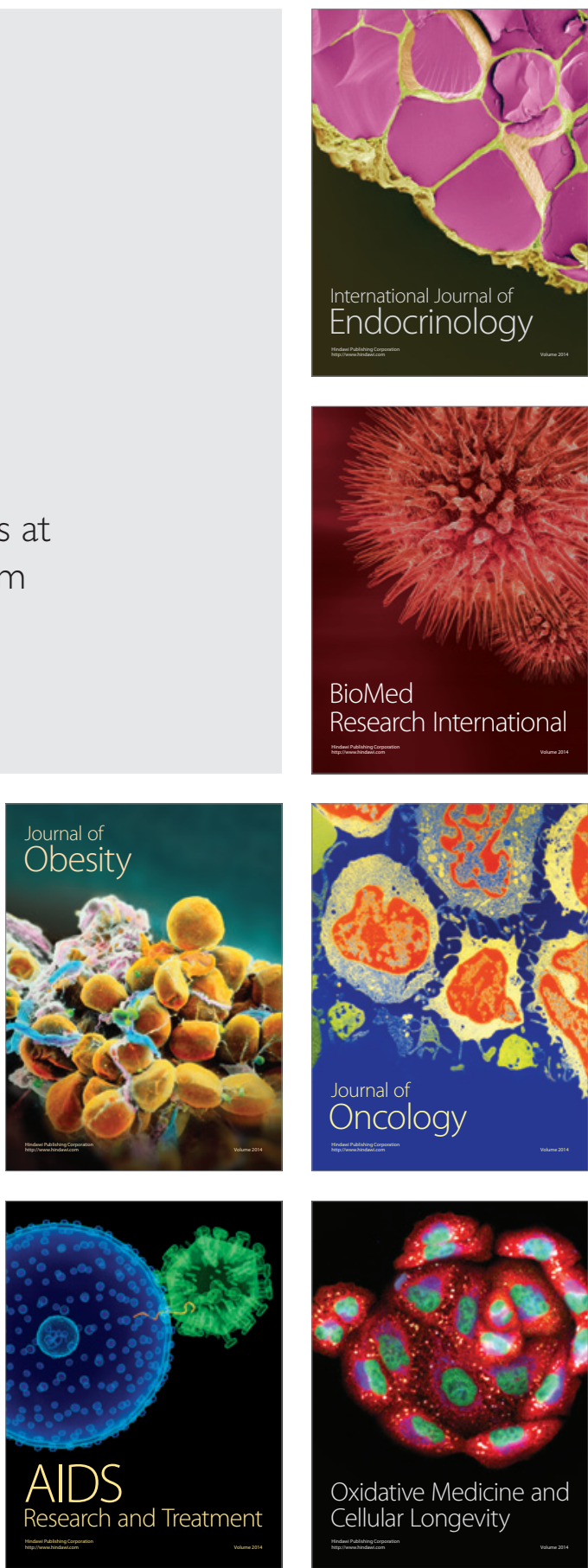